\title{
Title:
}

\section{Lomitapide, a cholesterol-lowering drug, is an anticancer agent that induces autophagic cell death via inhibiting mTOR}

\author{
Running title: \\ Lomitapide inhibits mTOR and cancer cell growth
}

Authors: Boah Lee ${ }^{1,2, *}$, Seung Ju Park ${ }^{2, *}$, Seulgi Lee ${ }^{2}$, Jinwook Lee ${ }^{3}$, Eunbeol Lee ${ }^{2}$, Eun-Seon Yoo $^{2}$, Won-Suk Chung ${ }^{2}$, Jong-Woo Sohn ${ }^{2}$, Byung-Chul Oh${ }^{3}$, Seyun Kim ${ }^{2,4}$

\begin{abstract}
Affiliations:
${ }^{1}$ Department of Bio and Brain Engineering, Korea Advanced Institute of Science and Technology (KAIST), Daejeon 34141, Korea.

${ }^{2}$ Department of Biological Sciences, KAIST, Daejeon 34141, Korea.

${ }^{3}$ Department of Physiology, Lee Gil Ya Cancer and Diabetes Institute, Gachon University, College of Medicine, Incheon 21999, Korea.

${ }^{4}$ KAIST Institute for the BioCentury, KAIST, Daejeon 34141, Korea.
\end{abstract}

$†$ Corresponding author. Email: seyunkim@kaist.ac.kr (S.K.)

* These authors contributed equally to this work. 


\begin{abstract}
Autophagy is a biological process that maintains cellular homeostasis and regulates the internal cellular environment. Hyperactivating autophagy to trigger cell death has been a suggested therapeutic strategy for cancer treatment. Mechanistic target of rapamycin (mTOR) is a crucial protein kinase that regulates autophagy; therefore, using a structure-based virtual screen analysis, we identified lomitapide, a cholesterol-lowering drug, as a potential mTOR complex 1 (mTORC1) inhibitor. Our results showed that lomitapide directly inhibits mTORC1 in vitro and induces autophagy-dependent cancer cell death by decreasing mTOR signaling, thereby inhibiting the downstream events associated with increased LC3 conversion in various cancer cells (e.g., HCT116 colorectal cancer cells) and tumor xenografts. Lomitapide also significantly suppresses the growth and viability along with elevated autophagy in patient-derived colorectal cancer organoids. Furthermore, a combination of lomitapide and immune checkpoint blocking antibodies synergistically inhibits tumor growth in murine MC-38 or B16-F10 pre-clinical syngeneic tumor models. These results elucidates the direct, tumor-relevant immune-potentiating benefits of mTORC1 inhibition by lomitapide, which complement the current immune checkpoint blockade. This study highlights the potential repurposing of lomitapide as a new therapeutic option for cancer treatment.
\end{abstract}

Keywords: cancer, autophagy, mTOR, virtual screen, lomitapide, tumor growth 


\section{Introduction}

Macroautophagy (hereafter referred to as autophagy) is a highly dynamic catabolic process involving the degradation of damaged organelles, misfolded proteins, and long-lived macromolecules in lysosomes ${ }^{1}$. Under basal conditions, this process degrades long-lived proteins; however, when cells are under stress, such as during starvation or hypoxia, autophagy is drastically elevated to enhance cell survival, thereby acting as a protective mechanism ${ }^{2}$. Autophagy is an orchestrated process involving several steps, initiated by the formation and elongation of the phagophore, which subsequently expands by acquiring lipids, and ultimately transforms into a completely sealed double membrane structure called the autophagosome ${ }^{3}$. The autophagosome then fuses with the lysosome to the form the autolysosome, where the sequestered cargo is degraded and recycled. This recycling process enables the cells to cope with various stress conditions and maintain cellular homeostasis. Autophagy is also involved in the progression of numerous disorders, such as cancer, auto-immune diseases, infections, and neurodegeneration ${ }^{4-6}$.

In the context of cancer, regulating autophagy can be a double-edged sword $^{7-9}$. On one hand, autophagy can become a crucial survival mechanism for tumor cells under various stresses. Activation of autophagy has been reported to have a protective effect on cancer cells undergoing anticancer treatments facing various stressful conditions, thereby leading to poor treatment outcomes and the development of treatment resistance ${ }^{10,11}$. On the other hand, emerging evidence has indicated that excess autophagy can lead to autophagic cell death ${ }^{12-14}$, also known as type II programmed cell death ${ }^{15}$. Preclinical studies have shown that genetic or pharmacological hyperactivation of autophagy can promote tumor regression, highlighting the potential of targeted autophagy as an effective therapeutic strategy for cancer ${ }^{9,16,17}$. Autophagic cell death can 
be triggered in different cancer cell types by various compounds including $\mathrm{BH} 3$ mimetics such as obatoclax and gossypol, histone deacetylase inhibitors, as well as natural plant products such as resveratrol and betulinic acid ${ }^{18,19}$.

The mTOR complex is the most important regulator of autophagy ${ }^{20}$. mTOR is a serine/threonine kinase that crucially functions as a cellular signaling network node, wherein extracellular and intracellular conditions are integrated by including growth factors, cellular stressors, and nutrients such as amino acids ${ }^{21}$. Therefore, mTOR signaling mediates a plethora of major biological events involved in growth and metabolism ${ }^{22,23}$. Throughout extensive proteinprotein interactions, mTOR exists as two multi-subunit complexes: mTOR complex 1 (mTORC1) and 2 (mTORC2). Activation of mTORC1 has been reported to promote cell growth by phosphorylating S6 kinase 1 (S6K1) and 4E-BP1 ${ }^{24}$. Stimulation of mTORC2 has been reported to lead to cell survival and actin cytoskeletal changes by phosphorylating Akt, protein kinase C, and serum/glucocorticoid regulated kinase $1^{20,21}$. Under nutrient-replete conditions, mTOR has been reported to block the initiation of autophagy by phosphorylating ULK $1^{25}$. Starvation or the pharmacologic inhibition of mTOR can cause its dissociation from the complex of ATG13 with ULK1 and ULK2, thereby triggering autophagosome formation and autophagy ${ }^{26}$. The dysregulation of the mTOR signaling pathway has also been linked with cancer, inflammation, diabetes, and neurological diseases ${ }^{27,28}$. In fact, $70 \%$ of all known cancers have been shown to be associated with aberrant hyperactivation of mTOR, which promotes cellular proliferation and delays the apoptosis of tumor cells ${ }^{29,30}$. Therefore, regulating the mTOR signaling pathway can result in cancer cell death with elevated autophagy, thereby highlighting its potential in the development of new cancer treatments ${ }^{31,32}$. 
Identifying therapeutic approaches to treat cancer is laborious, expensive, and often inefficient. Drug repurposing or repositioning in oncology refers to the application of drugs, which are already approved for other medical applications, in treating cancer. Compared to de novo drug discovery, the development risks, costs, and chances of safety-related failures are reduced with the use of repurposed drugs because their thoroughly researched pharmacokinetic and pharmacodynamic profiles are largely accessible ${ }^{33}$. Moreover, in order to enhance therapeutic benefits, repurposed drugs are often combined with frequent administrations of lowdose chemotherapy. Recent advancements in structure-based molecular docking and computational analyses have led to the development of in silico drug discovery approaches. Therefore, therapeutic discovery through a drug repurposing strategy aided by these technological advancements can potentially accelerate studies into clinical trials more rapidly compared to that using newly developed drugs.

In this study, we employed a structure-based virtual screening approach to identify an mTOR inhibitor candidate. Using in vivo cellular and biochemical experiments as well as transcriptome sequencing analyses, we identified lomitapide, an inhibitor of hepatic microsomal triglyceride transfer protein (MTTP) used to treat familial hypercholesterolemia, as an mTOR inhibitor. Mechanistically, lomitapide directly inhibits the kinase activity of mTOR and induces autophagy, thereby suppressing growth while increasing cancer cell death. Our results indicate that the U.S. FDA-approved drug, lomitapide, can be potentially repurposed for the treatment of cancer. 


\section{MATERIALS AND METHODS}

\section{Ethics statement}

All mice were housed in a pathogen-free animal facility at KAIST Laboratory Animal Resource Center. The animals were maintained in a temperature/humidity controlled room on a $12 \mathrm{~h}$ light/12 h dark cycle and fed a standard chow diet. All experiments involving animals were conducted according to the ethical policies and procedures approved by the Committee for Animal Care at KAIST.

\section{Molecular modeling}

Docking simulations using the Libdock algorithm ${ }^{34}$ in Discovery Studio 3.1 (Accelrys Inc., San Diego, USA) were performed with compounds. The X-ray crystal structure complex of ATPbound human mTORC1 (PDB ID: 4JSV) and cryo-EM structure of human mTORC2 (PDB ID: 5ZCS) were obtained from the protein data bank. The proposed binding site for mTORC1 was centered on the ligand and a site sphere was created at coordinates $-19.17,-31.85,-58.25$ with a 14.58 ̊ diameter and for mTORC2, sphere was generated at coordinates 196.59165.31 217.46 with a $16.34 \AA$ diameter including ATP binding residues according to the structure of mTORC1. The protocols included 100 hotspots with a docking tolerance of 0.25 . The FAST conformation method was also used with CHARMM.

\section{Fluorescence-based thermal shift assay}

The thermal shift assays were performed using the 7500 Real-Time PCR System (Applied Biosystems) melting curve program with a temperature increment of $1.0^{\circ} \mathrm{C}$ and a temperature range of $25-95^{\circ} \mathrm{C}$. All reactions were incubated in a $20 \mu \mathrm{l}$ final volume and assayed in 96 -well 
plates using 1:1,000 dilution of 5,000 $\times$ SYPRO Orange stock solution (Sigma-Aldrich) and indicated concentrations $(1.0 \mu \mathrm{M})$ of recombinant mTOR kinase domain diluted in buffer containing $10 \mathrm{mM}$ HEPES $\cdot \mathrm{HCl} \mathrm{pH}$ 7.5. Lomitapide was added to the reaction to assess liganddependent thermal destabilization of mTOR kinase domain protein. The ligands (dissolved in DMSO) were incubated with mTOR kinase domain protein at $4{ }^{\circ} \mathrm{C}$ for 25 min before acquiring the melting curves ${ }^{35}$. The Tm is identified by plotting the first derivative of the fluorescence emission as a function of temperature $(-\mathrm{dF} / \mathrm{dT})$ using GraphPad PRISM7 software.

\section{In vitro mTOR kinase assay}

For in vitro mTOR kinase assay, cells were rinsed once with ice-cold PBS and lysed in ice-cold CHAPS buffer. Cell lysates were incubated at $4{ }^{\circ} \mathrm{C}$ for $10 \mathrm{~min}$ and the supernatant was collected by centrifuging lysates at 13,000 rpm for $10 \mathrm{~min} .2 \mathrm{mg}$ of mTOR antibody were added to the 2 $\mathrm{mg}$ of cell lysates and incubated with rotation for $2 \mathrm{~h}$ at $4{ }^{\circ} \mathrm{C} .20 \mathrm{ml}$ of agarose beads (Pierce) were added and the incubation continued for an additional $1 \mathrm{~h}$. mTOR immunoprecipitates were washed twice with the same lysis buffer and twice with kinase wash buffer (25 mM HEPES at pH 7.4, $20 \mathrm{mM}$ potassium chloride, $1 \mathrm{mM}$ magnesium chloride). Kinase assays were performed for $15 \mathrm{~min}$ at $37^{\circ} \mathrm{C}$ in a final volume of $15 \mathrm{ml}$ of mTORC1 kinase buffer ( $25 \mathrm{mM}$ HEPES at $\mathrm{pH}$ 7.4, $50 \mathrm{mM} \mathrm{KCl}, 10 \mathrm{mM} \mathrm{MgCl} 2,500 \mu \mathrm{M} \mathrm{ATP})$ and $150 \mathrm{ng}$ of S6K1 as a substrate. Reactions were stopped by the addition of $10 \mathrm{ml}$ of sample buffer and boiling for $5 \mathrm{~min}$ and analyzed by SDS-PAGE and immunoblotting. In vitro mTORC2 kinase assay was performed by using mTORC2 kinase buffer (25 mM HEPES at $\mathrm{pH} 7.5,100 \mathrm{mM}$ potassium acetate, $1 \mathrm{mM} \mathrm{MgCl}_{2}$, $500 \mu \mathrm{M}$ ATP) with $100 \mathrm{ng}$ of Akt1 as a substrate. 


\section{Cell lines and culture conditions}

NCM460 cells (human colon normal cells), HCT116 cells (human colon cancer cells, p53 wild type), HT29 cells (human colon cancer cells, p53 mutant), SW480 cells (human colon cancer cells, p53 mutant), MDA-MB-231 cells (human breast cancer cells), MDA-MB-468 cells (human breast cancer cells), A375 (human skin cancer), and A2058 (human skin cancer) were purchased from ATCC (American Type Culture Collection, Virginia, USA) and used. HS756T (human stomach cancer), SNU1 (human stomach cancer), and SNU216 (human stomach cancer) cells were purchased from Korea Cell Line Bank. HCT116 cells were cultured in McCoy's 5a medium (Sigma Aldrich, Missouri, USA) supplemented with $2 \mathrm{mM}$ glutamine, $1 \%$ penicillinstreptomycin and $10 \%$ fetal bovine serum (FBS) at $37{ }^{\circ} \mathrm{C}$ and $5 \% \mathrm{CO}_{2}$. HT29 and SW480 cells were cultured in RPMI medium (Sigma Aldrich) supplemented with $2 \mathrm{mM}$ glutamine, $1 \%$ penicillin-streptomycin and $10 \% \mathrm{FBS}$ at $37{ }^{\circ} \mathrm{C}$ and $5 \% \mathrm{CO}_{2}$. MDA-MB-231, MDA-MB-468, A375, A2058, HS746T, SNU1, and SNU216 cells were supplemented with 2 mM glutamine, $1 \%$ penicillin-streptomycin and $10 \% \mathrm{FBS}$ in DMEM medium (Sigma Aldrich) at $37{ }^{\circ} \mathrm{C}$ and $5 \%$ $\mathrm{CO}_{2}$.

\section{Cancer cell viability screen}

High-throughput cancer cell viability assays were performed by Reaction Biology Corp. (Philadelphia, USA). 120 major cancer cell lines derived from skin, breast, brain, ovary, liver, stomach, kidney, bone, pancreas, intestine, lung, and blood cancer were inoculated in a 96-well plate at a density of $10^{4}$ cells/well, and cultured at $37{ }^{\circ} \mathrm{C}$ for $24 \mathrm{~h}$, followed by various concentrations $(0,1,2,5,10 \mu \mathrm{M})$ of lomitapide (Sigma Aldrich, Missouri, USA). The plate was incubated at $5 \% \mathrm{CO}_{2}$ at $37{ }^{\circ} \mathrm{C}$ for $24 \mathrm{~h}$ after treatment with lomitapide. Thereafter, cells were 
added to each well of $100 \mu \mathrm{l}$ of the assay reagent CellTiter-Glo® Reagent), and luminescence was measured using a VICTOR X Multilabel Reader (PerkinElmer, Massachusetts, USA).

\section{Colony forming assay}

In order to test the action of lomitapide in the control of cancer cell proliferation in the HCT116, HT29, and SW480 cell lines, the rate of cancer cell colony proliferation was examined by adding lomitapide to the wells in which cells were cultured. HCT116, HT29, and SW480 cells were inoculated in a 12-well plate at a density of $10^{5}$ cells/well and incubated at $37{ }^{\circ} \mathrm{C}$ for $24 \mathrm{~h}$, and then the cells were treated with $0,5 \mu \mathrm{M}$ concentration of lomitapide. After lomitapide treatment, the plate was incubated at $5 \% \mathrm{CO}_{2}$ at $37{ }^{\circ} \mathrm{C}$ for $48 \mathrm{~h}$. Thereafter, $500 \mu \mathrm{l}$ of crystal violet was added to each well, and cells were stained at room temperature for $10 \mathrm{~min}$ to analyze cell proliferation.

\section{Immunoblotting}

Levels of signaling protein expression and activity were measured with immunoblotting in various cancer cell lines. Lomitapide treated cells at various concentrations $(0,5,10 \mu \mathrm{M})$ were lysed with RIPA buffer (50 mM Tris-Cl pH 7.5, $150 \mathrm{mM} \mathrm{NaCl}, 1 \mathrm{mM}$ EDTA, $50 \mathrm{mM}$ sodium fluoride, $10 \mathrm{mM}$ sodium pyrophosphate, $10 \mathrm{mM}$ glycerophosphate, $1 \% \mathrm{NP}-40,0.25 \%$ sodium deoxycholate, $0.1 \%$ SDS) containing protease-inhibitor cocktail. Whole-cell lysate was incubated on ice for $30 \mathrm{~min}$, then centrifuged at $4{ }^{\circ} \mathrm{C}, 13,300 \times \mathrm{g}$ for $15 \mathrm{~min}$ and the supernatant was collected. As a control, cells treated with $1 \mu \mathrm{M}$ of Torrin1, known as an mTOR inhibitory compound, were used. For immunoblot analysis, the supernatant obtained above was loaded on a $10 \%$ SDS-PAGE gel to separate, and the separated protein was blotted onto a nitrocellulose 
membrane. Anti-p-AKT, anti-p-mTOR, anti-p-S6K, anti-p-S6, anti-p-ERK, anti-AKT, anti-S6K, anti-S6, anti-p-ULK1, and anti-LC3 (Cell Signaling Technology), anti-alpha-tublin antibody (Sigma Aldrich), and anti-GAPDH (Santa Cruz Biotechnology) were used. Antibodies were added and incubated at $4{ }^{\circ} \mathrm{C}$ for $12 \mathrm{~h}$. The blot was then washed with a mixture of tris-buffered saline (TBS) and Tween-20 (TBST) and horseradish peroxidase-conjugated secondary antibody (Cell signaling Technology) at $37{ }^{\circ} \mathrm{C}$. After incubation and washing for $1 \mathrm{~h}$, enhanced chemiluminescence (ECL; Biorad) was detected.

\section{RNA-sequencing analysis}

Total RNA was isolated from tissue using Maxwell (Promega) based method. $1 \mu \mathrm{g}$ of total RNA was processed for preparing mRNA sequencing library using MGIEasy RNA Directional Library Prep Kit (MGI) according to manufacturer's instruction. The first step involves purifying the poly-A containing mRNA molecules using poly-T oligo attached magnetic beads. Following purification, the mRNA is fragmented into small pieces using divalent cations under elevated temperature. The cleaved RNA fragments are copied into first strand cDNA using reverse transcriptase and random primers. Strand specificity is achieved in the RT directional buffer, followed by second strand cDNA synthesis. These cDNA fragments then have the addition of a single 'A' base and subsequent ligation of the adapter. The products are then purified and enriched with PCR to create the final cDNA library. The double stranded library is quantified using QauntiFluor ONE dsDNA System (Promega). The library is circularized at $37{ }^{\circ} \mathrm{C}$ for 30 min, and then digested at $37^{\circ} \mathrm{C}$ for $30 \mathrm{~min}$, followed by cleanup of circularization product. To make DNA nanoball (DNB), the library is incubated at $30{ }^{\circ} \mathrm{C}$ for 25 min using DNB enzyme. Finally, Library was quantified by QauntiFluor ssDNA System (Promega). Sequencing of the 
prepared DNB was conducted on the MGIseq system (MGI) with 150 bp paired-end reads. The limma, edgeR, msigdbr, clusterProfiler packages in $\mathrm{R}$, an open-source programming environment, was used to perform differentially expressed genes, gene set enrichment and pathway enrichment analysis. ENTREZID, MsigDB, GO terms and KEGG pathways were mapped and were used to perform enrichment test based on hypergeometric distribution. To prevent high false discovery rate (FDR) in multiple testing, q-values were also estimated for FDR control.

\section{Autophagy assays}

To confirm the association of lomitapide's ability to induce autophagy, 3-methylamine (3-MA) and bafilomycin (Sigma Aldrich) were used. LC3 level was determined under lomitapide treatment in the absence or presence of $1 \mathrm{mM} 3-\mathrm{MA}$ or bafilomycin. Cell viability was measured using CellTiter-Glo® Reagent.

\section{Immunofluorescence}

HT29 and HCT116 cells were fixed with $4 \%$ paraformaldehyde, permeabilized with $0.1 \%$

TrintonX-100 in DPBS, and blocked with $3 \%$ goat serum. Then cells were stained with antiGFP, anti-LC3B (Cell signaling technology), and anti-LAMP2 antibody (Santa Cruz Biotechnology), and counterstained with DAPI (Thermo). Image taking and processing were carried out with laser scanning confocal microscopy (Carl Zeiss AG, Jena, Thuringia, Germany). Visualization and picture in the same panel were taken under the same excitation conditions. Fresh frozen tumor tissues were sectioned at $10 \mu \mathrm{m}$ with a cryostat. Anti-CD8, anti-PD-L1, antiCD8, and DAPI were used for detection. 


\section{Caspase 3/7 assays}

Caspase activity was measured from HCT116 and HT29 cells treated with lomitapide for $24 \mathrm{~h}$. Etoposide was used as control for the induction of apoptosis. Z-VAD was used as control for the inhibition of apoptosis.

\section{Viability assay of organoids derived from colorectal cancer patients}

The anticancer effect of lomitapide on CRC organoids were analyzed by Organoid Sciences (Pangyo, Korea). Organoid derived from colorectal cancer patients (CRC01 from 46-year-old male, CRC02 from 74-year-old female) were cultured for 5-7 days in 48-well plates. Cytation5 (Biotek), a high-content imaging-based screening device, was used to analyze organoids. After removing the culture medium from the organoids so that they would not separate from the plate, the organoids were transferred to new tubes by pipetting them with $1,000 \mu$ of DPBS. The tubes with organoids were centrifuged at $1,350 \mathrm{rpm}$ for $5 \mathrm{~min}$, and the supernatant was removed. Organoids were stained with Hoechst33342 (Thermo, \#H-1339) for 30 min at $37{ }^{\circ} \mathrm{C}$ in a $5 \%$ $\mathrm{CO}_{2}$ incubator. After staining, the tube with organoids were centrifuged at 1,350 rpm for $5 \mathrm{~min}$, and the supernatant was removed. Next, $100 \mu \mathrm{l}$ of organoid culture solution was added to the organoids, mixed with the organoids via pipetting, and centrifuged at $1,350 \mathrm{rpm}$ for $5 \mathrm{~min}$, the supernatant was removed. Cell pellets were resuspended in 1:1 mixture of growth medium and Matrigel, and then seeded in 96-well black plates at a density of 150-200 cells/well. The Matrigel was polymerized for $10 \mathrm{~min}$ at $37^{\circ} \mathrm{C}$, and the culture medium with PI and drugs was added to the wells. Cytation5 (Biotek) was used to identify the number, morphology, and area of organoids via a DAPI signal. Then, without changing the culture solution, changes in organoid area were observed every $24 \mathrm{~h}$ for $72 \mathrm{~h}$. Based on the raw data from the Cytation 5 device, the 
efficacy of the drug was calculated using the formula below. The overall efficacy of a drug at a specific concentration is defined as the percentage of organoid growth inhibition and organoid death. The area of organoids stained with Hoechst33342 $\left(\mu \mathrm{m}^{2}\right)$ was observed with Cytation5, and the areas of all organoids in each well were added. The difference in organoid areas was calculated by subtracting the initial area of the organoids (at $0 \mathrm{~h}$ post-treatment) from the final area of the organoids (at $72 \mathrm{~h}$ post-treatment).

\section{In vivo xenograft assay}

In order to confirm the effect of lomitapide anticancer in a mouse xenograft model, changes in tumor size were examined after treatment with lomitapide in mice transplanted with tumors. HCT116 $\left(2 \times 10^{6}\right)$ and HT29 $\left(5 \times 10^{6}\right)$ cells were implanted subcutaneously into 8-12 weeks old male BALB/c nude mice. After the average tumor volume reached $50 \mathrm{~mm}^{3}$, mice were randomly assigned to 2 different groups (6 animals / group). Mice's body weight and tumor diameter were measured once every other days. Tumor volume was evaluated according to the general formula $0.5 \mathrm{x}$ (width $)^{2} \mathrm{x}$ (length) using a caliper, and Student's T test was used to determine p-values. For treatment with lomitapide, 10, 20,25, $50 \mathrm{mg} / \mathrm{kg}$ of lomitapide was injected intraperitoneal into mice as indicated. The experiment was conducted in the same way as above for 10 days at 2 days intervals, also the intratumorally injection method was applied for 10 days at 5 injection intervals.

\section{Immunohistochemistry}

Tissues and tumors were embedded in paraffin, and $5 \mu \mathrm{m}$ sections were prepared and stained with Hematoxylin and eosin Y solution (H\&E) for histologic evaluation via light microscopy. For immunohistochemical staining of Ki67, we used paraffin embedded sections $(5 \mu \mathrm{m})$ of 
mouse tumor tissue. We performed heat mediated antigen retrieval in citrate buffer ( $\mathrm{pH} \mathrm{6.0).}$ Deparaffinized tissue-sections were incubated with primary antibody of Ki67 (1:200; ab15580 Abcam). Staining was visualized by using Mouse Specific HRP/DAB Detection IHC Kit (ab64259 Abcam) and sections were counterstained with Mayer's hematoxylin. Sections were photomicrographed with a digital camera mounted on light microscope (Olympus BX51, Japan), digitized and analyzed. Analysis was performed on 10 fields of a section at 40x magnification.

\section{Mouse tumorigenesis and treatment}

For the syngeneic tumor mouse model, experiments were conducted using two types of MC38 colorectal cancer and B16F10 cutaneous melanoma cell lines in female C57B6/N mice (wildtype, 6-week-old). MC38 colorectal cancer and B16F10 cutaneous melanoma cells were injected subcutaneously at $2 \times 10^{5}$. Lomitapide used in both models was formulated with $45 \%$ saline, $40 \%$ PEG300, $5 \%$ Tween-80, and $10 \%$ DMSO. For MC38 colorectal cancer, lomitapide was administered intraperitoneally at a dose of $20 \mathrm{mg} / \mathrm{kg}$ from 10 days after tumor injection for 5 doses, and 10 mg/kg anti-PD-1 mAb (clone RMP1-14, BioXCell, West Lebanon, NH, USA) or a rat IgG2a isotype control (clone 2A3, BioXCell, BE0089) were administered on days 1, 4, 7, and 10 in PBS. In the case of B16F10 cutaneous melanoma, lomitapide was administered at a dose of $20 \mathrm{mg} / \mathrm{kg}$ three times intraperitoneally on days 3, 5, and 7 from 10 days after tumor injection, and $7.5 \mathrm{mg} / \mathrm{kg}$ anti-PD-1 mAb (clone RMP1-14, BioXCell, West Lebanon, NH, USA) or rat IgG2a isotype control (clone 2A3, BioXCell, BE0089) were administered on days 1, 3, 5, and 7 in PBS. Mice were immediately euthanized when signs of distress were observed, $20 \%$ weight loss of normal body weight, or tumor volume exceeded $1000 \mathrm{~mm}^{3}$. 


\section{Results}

\section{Lomitapide inhibits mTORC1 in vitro}

To investigate novel anti-neoplastic agents in a cost-effective way, we designed in silico structure-based modeling of mTOR as its druggable potential ${ }^{36}$. We strategized to obtain promising mTOR inhibitors within already approved drugs maximizing therapeutic benefits while avoiding risks of toxicity. In order to repurpose medications from a public database that included FDA-approved drugs, we screened to characterize the interactions of the crystalline structure of human mTORC1 (PDB 4JSV15) ${ }^{37}$ (Fig. 1a) with the structures of over 3,000 compounds. Of these top-ranked compounds from initial screening, we focused on lomitapide because it fits our criteria of drug repositioning strategy; i) originally approved not for cancer treatment, ii) currently used as a cure for orphan (rare) diseases. This compound was firstly developed to treat a rare genetic disease, hypercholesterolemia, by inhibiting the hepatic MTTP ${ }^{38}$ (Fig. 1b). Our docking models revealed that lomitapide specifically binds to the ATP-binding catalytic core of mTORC1, including the H2189, D2190, L2192, Q2194, D2195, D2338, and D2357 residues (Fig. 1c). Interestingly, lomitapide failed to interact with mTORC2 (PDB 5ZCS17) according to the docking analysis, suggesting that there was no interaction between lomitapide and mTORC2.

We tested direct interaction between lomitapide and purified mTOR kinase domain. The thermal stability of recombinant mTOR kinase domain was evaluated by varying concentrations of lomitapide. We found that lomitapide reduced the thermal stability of recombinant mTOR kinase domain in a concentration-dependent manner, i.e. $50 \mu \mathrm{M}$ of lomitapide decreased the Tm by approximately $2.4{ }^{\circ} \mathrm{C}$ (Fig. 1d, e), suggesting that lomitapide binds to the kinase domain of mTOR and affects its kinase activity. Next, in vitro mTOR kinase assays were performed using 
mTOR immunoprecipitates prepared from HEK 293T cells to determine whether lomitapide directly influences mTOR activity. Lomitapide dose-dependently inhibited the phosphorylation of the T389 residue of S6K1, a major substrate of mTORC1, suggesting its direct role in inhibiting mTORC1 (Fig. 1f). However, this inhibitory effect of lomitapide was not observed in the mTORC2 kinase assay using Akt as the substrate (Fig. 1g). These results indicate that lomitapide selectively inhibits mTOR activity by only inhibiting mTORC1 and not mTORC2. Results of our docking analysis shown in Fig. 1c prompted us to further test the inhibition of lomitapide in competition with ATP. In vitro mTORC1 kinase assays demonstrated that the inhibition of mTORC1 by lomitapide was reversed by increasing ATP concentrations (Fig. 1h), suggesting that lomitapide competes with ATP to directly interact with the kinase domain in order to inhibit mTORC1.

\section{Lomitapide inhibits cancer cell growth and mTOR signaling}

Next, we examined whether lomitapide substantially impacts cellular growth, which is the primary event that mTOR controls. Lomitapide treatment significantly reduced the viability of multiple colorectal cancer (CRC) cell lines (HCT116, HT29, and SW480), but not of NCM460, a normal human colon mucosal epithelial cell (Fig. 2a, Supplementary Fig. 1). We also found that lomitapide treatment markedly inhibited the colony formation of our CRC cell lines (Fig. 2b). The expression levels of MTTP, lomitapide's known target, were undetected in our CRC cells, suggesting that the anticancer activity of lomitapide was independent of its known target, MTTP (Supplementary Fig. 2).

In order to investigate the role of lomitapide in cellular mTOR signaling events, CRC cells were treated with lomitapide for $4 \mathrm{~h}$, after which reduced phosphorylation was observed at 
T389 of S6K1, S240/244 of S6, and T37/46 of 4E-BP1, but not at S473 of Akt nor at T202/Y204

of Erk (Fig. 2c). As demonstrated by the mTOR kinase assay (Fig. 1f, h), lomitapide selectively inhibited mTORC1 in cells. Expectedly, we found that the levels of the autophagosomal marker LC3-II increased with lomitapide treatment, which decreased the phosphorylation of the mTORC1-sensitive S757 residue of Ulk1 (Fig. 2d), suggesting the induction of autophagy by lomitapide-triggered mTORC1 inhibition. In other breast, skin, and stomach cancer cell lines (e.g. MDA-MB-231, MDA-MB-468, A375, A2058, HS-746T, SNU1, SNU216), lomitapide treatment also led to inhibition of mTORC1 signaling and accompanied LC3-II induction (Supplementary Fig. 3). Further analyses using a panel of 120 different cancer cell lines revealed that lomitapide reduced the viability of all cancer cells (IC50 $=1.5 \sim 5 \mu \mathrm{M})$ (Supplementary Table 1$)$, revealing its broad spectrum anticancer effect. On the basis of these data, we conclude that lomitapide inhibits mTORC1 signaling and impairs cancer cell growth and viability.

\section{Lomitapide induces autophagic cell death}

In order to understand the molecular-level changes in cancer cells treated with lomitapide, we performed RNA-Seq analyses and found that lomitapide significantly impacted the autophagy-related genes, which supported the activation of autophagy by mTOR inhibition (Fig. 3a, b and Supplementary Table 2). To further validate whether the autophagy machinery was triggered by lomitapide treatment, HT29 cells were transfected with green fluorescent proteinLC3 (GFP-LC3), a specific marker of autophagic vesicles and autophagic activity (Fig. 3c). As shown in Fig. 3c, lomitapide treatment significantly increased the number of GFP-LC3 puncta compared with the control group, demonstrating lomitapide-induced autophagy. Similar autophagy induction phenotypes were also observed from lomitapide-treated HCT116 cells 
(Supplementary Fig. 4a, b). Importantly, reduced cell viability caused by lomitapide treatment was significantly restored when HT29 cells were treated with bafilomycin, a V-ATPase inhibitor that blocks autophagic flux, indicating that lomitapide's anticancer effect is primarily caused by inducing autophagic cell death (Fig. 3d). HCT116 cell viability was also rescued under 3methyladenine (3-MA), a class III phosphatidylinositol 3-kinase, treatment (Supplementary Fig. 4c). Inhibition of autophagy by 3-MA was similarly able to protect lomitapide-induced increase of LC3-II in HT29 cells (Fig. 3e) and HCT116 cells (Supplementary Fig. 4d). Knockdown of ATG7 or Beclin-1 was also found to diminish the levels of LC3-II increased by lomitapide treatment in HT29 cells (Fig. 3f) and HCT116 cells (Supplementary Fig. 4e), which validates the lomitapide-mediated activation of autophagy system. We further measured caspase activity to investigate the effect of lomitapide on apoptosis; however, lomitapide-treated CRC cells exhibited negligible induction of caspase 3/7 activities (Supplementary Fig. 5), suggesting no induction of apoptosis. These results thus demonstrate that hyperactivation of autophagy is the prime event underlying lomitapide-triggered cancer cell death.

\section{Lomitapide inhibits the growth of tumor xenografts}

After in vitro studies using cancer cell lines, the effects of lomitapide on tumor growth were examined in vivo by injecting $\mathrm{CRC}$ cells subcutaneously into immunocompromised mice and then monitoring tumor growth. The growth of both HT29 and HCT116 CRC xenografts was markedly inhibited by lomitapide treatment (Fig. 4a, b and Supplementary Fig. 6) confirming its anticancer effects in vivo. Lomitapide treatment did not influence body weight, indicating no apparent toxicity (Fig. 4c). Hematoxylin and eosin (H\&E) staining of tumor tissues of lomitapide treated groups showed more neoplastic lesions compared to vehicle groups (Fig. 4d). Through 
immunohistochemical staining, we further observed that the expression of Ki67 in lomitapidetreated HT29 xenografts was lowered (Fig. 4e). Taken together, these results suggest the therapeutic value and safety of lomitapide as an anticancer agent.

\section{Lomitapide inhibits growth of patient-derived CRC organoids}

We next investigated whether the lomitapide's inhibitory effect could also be confirmed in human tumor organoids that are three-dimensional ex-vivo model having the advantage of retaining the characteristics of the cancer cells from the original patients. When two different patient-derived $\mathrm{CRC}$ organoid lines were treated with $10 \mu \mathrm{M}$ lomitapide, organoid viability as measured from the size of live organoid cells was markedly reduced (Fig. 5a). Importantly, organoid viability of lomitapide-treated organoids was dramatically reduced compared to that of the organoids treated with $10 \mu \mathrm{M}$ 5-fluorouracil (5-FU), a first-line chemotherapeutic drug for CRC (Fig. 5a). $72 \mathrm{~h}$ treatment of lomitapide dose-dependently increased propidium iodide (PI)stained dead cells in CRC organoids, whereas 5-FU treatment showed only modest impact on cell viability (Fig. 5b), validating the potent anticancer action of lomitapide. H\&E staining further showed a substantial decrease in tumor organoid size in response to lomitapide but not vehicle (Fig. 5c). LC3-II levels were robustly increased by treatment with lomitapide but not with 5-FU (Fig. 5d). Consistent with findings from cancer cell lines and tumor xenografts, these results based on cancer organoid models validate that lomitapide is a potent antitumor drug to trigger autophagic cancer cell death.

\section{Lomitapide enhances the therapeutic effect of anti-PD-1}


Targeting antibodies to programmed cell death protein-1 (PD-1) is an effective treatment for various cancer types ${ }^{39,40}$. Although some patients receiving anti-PD-1 therapies respond favorably, most patients undergo disease progression without any clinical benefit ${ }^{41-43}$; this highlights the importance of combining therapies that enhance anti-tumor immunity. Recently, mTOR inhibitors in combination with anti-PD-1 have been reported to provide more durable and synergistic tumor regression than that by either agent alone ${ }^{44,45}$. Therefore, we assessed the impact of this combined treatment of antibody-mediated PD-1 blockade along with lomitapide on tumor growth, thereby determining whether it could improve the responsiveness to anti-PD-1 therapy. Our results showed that lomitapide treatment alone decreased the tumor growth in two syngeneic murine models, mouse colon cancer MC38 and melanoma B16-F10 models respectively (Fig. 6a, b and Supplementary Fig. 7a, b). Importantly, the combined treatment with lomitapide and anti-PD-1 antibody significantly inhibited tumor growth compared anti-PD-1 antibody treatment alone, in both MC38 and B16-F10 tumor models (Fig. 6a, b and Supplementary Fig. 7a, b). Immunohistochemical staining for tumor tissue sections revealed that the combination of anti-PD-1 antibody and lomitapide significantly increased infiltration of $\mathrm{CD}^{+} \mathrm{T}$ cell populations into tumor (Fig. 6c and Supplementary Fig. 7c). Collectively, our results provided strong evidence that combining lomitapide makes tumor-bearing mice responders to anti-PD-1 therapy.

\section{Discussion}

Upregulated mTOR signaling activities and hyperactive MTOR mutations have been reported in various types of cancer $^{27,29,30}$. Therefore, it is essential to discover therapeutic interventions that can inhibit mTOR actions. In this study, we performed in silico screening of 
mTOR-binding compounds and identified lomitapide, a FDA-approved drug, as a candidate to inhibit mTOR and its signaling in cancer cell growth. In vitro characterization of lomitapide's inhibition of mTOR and analysis of its impact in cancer cells demonstrates lomitapide's inhibition of mTORC1. Suppression of mTORC1 signaling in lomitapide-treated cancer cells and human CRC organoids triggers a robust induction of autophagy, which mainly drives lomitapidemediated cancer cell death. The inhibitory effect of lomitapide on cancer cell growth was also validated in vivo using tumor xenograft models. Furthermore, combining lomitapide treatment significantly enhances the efficacy of anti-PD-1 therapy in reducing the growth of tumors in CRC and melanoma; this establishes efficacious anticancer effects of lomitapide across multiple different cancer types in preclinical in vivo models. Therefore, our drug repurposing strategy, starting from virtual screening to validation and from mechanistic analyses to in vivo characterizations, represents an illustrative model that can be potentially valuable for the next generation of translational medicine.

Lomitapide was originally approved by the FDA for therapeutic use to treat homozygous familial hypercholesterolemia, a serious rare inherited medical condition that leads to extremely high levels of low-density lipoprotein cholesterol ${ }^{38}$. Mechanistically, lomitapide acts in the liver by inhibiting microsomal triglyceride transfer protein (MTTP) that is required to assemble the low-density lipoprotein particle ${ }^{46}$. We completely ruled out the possibility that lomitapide's anticancer effects might be mediated by its action on MTTP. There was no data supporting the proto-oncogenic role of MTTP, which is expressed in the liver and the intestine. Conditional deletion of hepatic MTTP in mice has been linked to alterations in liver metabolism, but not to hepatic cellular growth defects ${ }^{47}$. Intestine-specific knockout of murine MTTP rather increased the tumor burden in a colitis-associated carcinogenesis model ${ }^{48}$. Importantly, we observed no 
notable expression of MTTP in CRC cell lines examined in this study. Therefore, we suggest that the anticancer effects of lomitapide in cancer cells strongly implicates its engagement of mTOR and not MTTP.

Collectively, our studies elucidate that lomitapide-mediated inhibition of mTORC1 signaling leads to the autophagic death of cancer cells. Lomitapide-treated cancer cells exhibited a robust induction of LC3-II with no signs of activated apoptosis (caspase 3/7). Pharmacological intervention of autophagy further reduced the already lowered cancer cell viability by lomitapide treatment, validating autophagic cell death as the primary mechanism of lomitapide's anticancer effects. During the preparation of this manuscript, Zuo et al. reported a role for lomitapide in the control of cancer cell death ${ }^{49}$, which is consistent with our findings. These authors reported that lomitapide suppresses the dephosphorylation of AMPK by directly inhibiting protein phosphatase 2A (PP2A). In light of our results and Zuo et al.'s report, we thus posit that lomitapide's anticancer activity can be mediated throughout targeting multiple signaling hubs including mTORC1 and PP2A controlling autophagy ${ }^{49}$.

Autophagy is a physiological homeostatic process involved in cellular protection through the degradation of aged and misfolded proteins as well as damaged organelles such as mitochondria. In normal cells, amino acid deprivation or glucose depletion is a canonical signal to inactive mTORC1 to turn on, thereby elevating autophagic fluxes. When induced in excess, autophagy can result in cancer cell death by intensifying self-digesting autophagosomal activities. Our results demonstrate that the contribution of this hyperactive autophagy is critical in determining the ultimate fate of cancer cells. In addition to mTOR inhibitors, other autophagyinducing drugs have been identified to treat cancer ${ }^{16-19}$. For example, gossypol, a pan-Bcl-2 inhibitor, was reported to trigger autophagic cell death in malignant gliomas ${ }^{50}$. Notably, both 
lomitapide-triggered autophagic induction and tumor growth suppression were consistently detected in patient-derived CRC organoid cultures, which reflect the heterogeneous nature of CRC. Compared to 5-FU, a first-line chemotherapeutic treatment for CRC, lomitapide exhibited autophagy activation with potent suppression of tumor organoid growth, signifying its therapeutic value as an anticancer drug. Although the results presented here are encouraging, the exact mechanism by which lomitapide influences cellular mTORC1 but not mTORC2 still needs to be understood. Furthermore, whether mTORC1 inhibition is the only way or one of several ways by which lomitapide induces autophagy still remains to be investigated. Considering contexts wherein autophagy can be utilized as a survival strategy to promote cancer cell survival, the therapeutic conditions of lomitapide in should be further refined. However, taken together, our results suggest the potential clinical use of lomitapide to treat these devastating tumors.

As with conventional cancer therapies, strategies to enhance clinical responses with immune checkpoint blockade are being investigated to provide breakthroughs in clinical immuno-oncology. Therefore, extensive pharmacological and clinical trials are currently underway to determine the safety and efficacy of combining current immune checkpoint drugs with conventional cancer treatments and immunomodulatory agents. We demonstrated that lomitapide markedly improves anti-tumor responses conferred by anti-PD-1 administration in syngeneic colon cancer MC38 and melanoma B16-F10 models, thereby potentially extending the scope for its potential use in combination with other therapies. Lomitapide alone also caused a comparable suppression of tumor growth in these models; therefore, we speculate that lomitapide-induced cancer cell death increases neoantigen production to stimulate an anti-tumor immune response in the tumor microenvironment. Similar to the results of previous studies using mTOR inhibitors, PD-L1 expression in cancer cells could be reduced by lomitapide treatment, 
suggesting its tumor-intrinsic effects. Modulating the tumor-extrinsic activities of mTOR signaling has also been known to determine the anti-tumor response induced by anti-PD-1 therapy. Typically, mTOR inhibition (e.g., rapamycin and rapalogs) has been understood to elicit immunosuppression; however, recent reports indicate potential immune-boosting functions following the pharmacological or genetic ablation of mTOR signaling pathways ${ }^{44,45}$. For instance, induction of CD8 memory $\mathrm{T}$ cell formation or reduction of myeloid-derived suppressor cells appear to be controlled by mTOR inhibition ${ }^{51,52}$. Following our discovery of lomitapide as a candidate for synergistic combination therapy, additional studies are required to evaluate the additional impact of lomitapide on shaping host immunity in the tumor microenvironment.

Collectively, our findings demonstrate that structure-based drug discovery approaches can be used to identify potential drugs to inhibit mTOR signaling. By providing multiple lines of evidence, we reveal that the lipid-lowering drug, lomitapide, possesses an autophagy-mediated anti-tumoral effect through mTOR pathway regulation. Lomitapide has already been established as a safe drug to treat familial hypercholesterolemia in humans. Its side effect profile is generally more favorable than that of most drugs typically used to treat cancer. These results suggest the importance of conducting clinical investigations into the use of lomitapide to treat cancer patients. 
Acknowledgments: We thank all the members of the Kim lab for discussion and helpful comments. Author Contributions: B.L., S.J.P. and S.K. conceived the study. B.L., S.J.P., S.L., J.L. performed experiments. B.L., S.J.P., B.O., and S.K. analyzed data. E.B.L., E.Y., W.C., and J. S. provided reagents and comments. B.L., S.J.P. and S.K. wrote the manuscript. S.K. supervised the research. Funding: This work was supported by KAIST Advanced Institute for Science-X Fellowship (to S.J.P.) and the National Research Foundation of Korea (NRF2020R1I1A1A01073144 to S.J.P.; NRF-2018R1A5A1024261 and 2020R1A2C3005765 to S.K.). Competing interests: B.L., S.J.P., and S.K. are listed on the patent entitled "Composition for treating colorectal cancer comprising lomitapide thereof as an active ingredient" (submission date: 21 February 2020; application number: 10-2020-0021549; country: Republic of Korea; issuing institution: Korea Advanced Institute of Science and Technology). The other authors declare that they have no competing interests. Data availability: All data needed to evaluate the conclusions in the paper are present in the paper and/or the Supplementary information. All other data are available from the corresponding author upon reasonable request. 


\section{References}

1. G. Kroemer, G. Mariño, B. Levine, Autophagy and the integrated stress response. Mol. Cell 40, 280-293 (2010).

2. H. Morishita, N. Mizushima, Diverse cellular roles of autophagy. Annu. Rev. Cell Dev. Biol. 35, 453-475 (2019).

3. C. A. Lamb, T. Yoshimori, S. A. Tooze, The autophagosome: origins unknown, biogenesis complex. Nat. Rev. Mol. Cell Biol. 14, 759-774 (2013).

4. N. Mizushima, B. Levine, A. M. Cuervo, D. J. Klionsky, Autophagy fights disease through cellular self-digestion. Nature 451, 1069-1075 (2008).

5. I. Dikic, Z. Elazar, Mechanism and medical implications of mammalian autophagy. Nat. Rev. Mol. Cell Biol. 19, 349-364 (2018).

6. V. Deretic, Autophagy in inflammation, infection, and immunometabolism. Immunity 54, $437-453$ (2021).

7. R. Amaravadi, A. C. Kimmelman, E. White, Recent insights into the function of autophagy in cancer. Genes Dev. 30, 1913-1930 (2016).

8. R. K. Amaravadi, A. C. Kimmelman, J. Debnath, Targeting autophagy in cancer: recent advances and future directions. Cancer Discov. 9, 1167-1181 (2019).

9. J. M. Mulcahy Levy, C. G. Towers, A. Thorburn, Targeting autophagy in cancer. Nat. Rev. Cancer 17, 528-542 (2017).

10. M. S. Sosa, P. Bragado, J. A. Aguirre-Ghiso, Mechanisms of disseminated cancer cell dormancy: an awakening field. Nat. Rev. Cancer 14, 611-622 (2014). 
11. K. Degenhardt, R. Mathew, B. Beaudoin, K. Bray, D. Anderson, G. Chen, C. Mukherjee, Y. Shi, C. Gélinas, Y. Fan, D. A. Nelson, S. Jin, E. White, Autophagy promotes tumor cell survival and restricts necrosis, inflammation, and tumorigenesis. Cancer Cell 10, $51-64$ (2006).

12. F. Napoletano, O. Baron, P. Vandenabeele, B. Mollereau, M. Fanto, Intersections between regulated cell death and autophagy. Trends Cell Biol. 29, 323-338 (2019).

13. S. Fulda, D. Kögel, Cell death by autophagy: emerging molecular mechanisms and implications for cancer therapy. Oncogene 34, 5105-5113 (2015).

14. R. Chavez-Dominguez, M. Perez-Medina, J. S. Lopez-Gonzalez, M. Galicia-Velasco, D. Aguilar-Cazares, The double-edge sword of autophagy in cancer: from tumor suppression to pro-tumor activity. Front. Oncol. 10, 578418 (2020).

15. L. Galluzzi, I. Vitale, G. Kroemer, Molecular mechanisms of cell death: recommendations of the Nomenclature Committee on Cell Death 2018. Cell Death Differ. 25, 486-541 (2018).

16. S. Deng, M. K. Shanmugam, A. P. Kumar, C. T. Yap, G. Sethi, A. Bishayee, Targeting autophagy using natural compounds for cancer prevention and therapy. Cancer 125, $1228-1246$ (2019).

17. X. Sui, R. Chen, Z. Wang, Z. Huang, N. Kong, M. Zhang, W. Han, F. Lou, J. Yang, Q. Zhang, X. Wang, C. He, H. Pan, Autophagy and chemotherapy resistance: A promising therapeutic target for cancer treatment. Cell Death Dis. 4, e838 (2013).

18. A. W. Opipari, L. Tan, A. E. Boitano, D. R. Sorenson, A. Aurora, J. R. Liu, Resveratrol- 
induced autophagocytosis in ovarian cancer cells. Cancer Res. 64, 696-703 (2004).

19. P. Gonzalez, I. Mader, A. Tchoghandjian, S. Enzenmüller, S. Cristofanon, F. Basit, K. M. Debatin, S. Fulda, Impairment of lysosomal integrity by B10, a glycosylated derivative of betulinic acid, leads to lysosomal cell death and converts autophagy into a detrimental process. Cell Death Differ. 19, 1337-1346 (2012).

20. G. Y. Liu, D. M. Sabatini, mTOR at the nexus of nutrition, growth, ageing and disease. Nat. Rev. Mol. Cell Biol. 21, 183-203 (2020).

21. X. M. Ma, J. Blenis, Molecular mechanisms of mTOR-mediated translational control. Nat. Rev. Mol. Cell Biol. 10, 307-318 (2009).

22. M. Shimobayashi, M. N. Hall, Making new contacts: the mTOR network in metabolism and signalling crosstalk. Nat. Rev. Mol. Cell Biol. 15, 155-162 (2014).

23. R. A. Saxton, D. M. Sabatini, mTOR signaling in growth, metabolism, and disease. Cell 168, 960-976 (2017).

24. I. Ben-Sahra, B. D. Manning, mTORC1 signaling and the metabolic control of cell growth. Curr. Opin. Cell Biol. 45, 72-82 (2017).

25. J. Kim, M. Kundu, B. Viollet, K. L. Guan, AMPK and mTOR regulate autophagy through direct phosphorylation of Ulk1. Nat. Cell Biol. 13, 132-141 (2011).

26. S. Alers, A. S. Löffler, S. Wesselborg, B. Stork, Role of AMPK-mTOR-Ulk1/2 in the regulation of autophagy: cross talk, shortcuts, and feedbacks. Mol. Cell Biol. 32, 2-11 (2012).

27. E. Dazert, M. N. Hall, mTOR signaling in disease. Curr. Opin. Cell Biol. 23, 744-755 
(2011).

28. P. B. Crino, The mTOR signalling cascade: paving new roads to cure neurological disease. Nat. Rev. Neurol. 12, 379-392 (2016).

29. S. Menon, B. D. Manning, Common corruption of the mTOR signaling network in human tumors. Oncogene 27, S43-S51 (2008).

30. B. C. Grabiner, V. Nardi, K. Birsoy, R. Possemato, K. Shen, S. Sinha, A. Jordan, A. H. Beck, D. M. Sabatini, A diverse array of cancer-associated mTOR mutations are hyperactivating and can predict rapamycin sensitivity. Cancer Discov. 4, 554-563 (2014).

31. M. Moschetta, A. Reale, C. Marasco, A. Vacca, M. R. Carratù, Therapeutic targeting of the mTOR-signalling pathway in cancer: benefits and limitations. Br. J. Pharmacol. 171, $3801-3813(2014)$

32. M. R. Janes, J. J. Limon, L. So, J. Chen, R. J. Lim, M. A. Chavez, C. Vu, M. B. Lilly, S. Mallya, S. T. Ong, M. Konopleva, M. B. Martin, P. Ren, Y. Liu, C. Rommel, D. A. Fruman, Effective and selective targeting of leukemia cells using a TORC1/2 kinase inhibitor. Nat. Med. 16, 205-213 (2010).

33. S. Pushpakom, F. Iorio, P. A. Eyers, K. J. Escott, S. Hopper, A. Wells, A. Doig, T. Guilliams, J. Latimer, C. McNamee, A. Norris, P. Sanseau, D. Cavalla, M. Pirmohamed, Drug repurposing: progress, challenges and recommendations. Nat. Rev. Drug Discov. 18, 41-58 (2019).

34. S. Rao, M. Head, A. Kulkarni, and J. LaLonde, Validation Studies of the Site-Directed 
Docking Program LibDock. J. Chem. Inf. Model. 47, 2159-2171 (2007).

35. K. Huynh, and C.L. Partch, Analysis of Protein Stability and Ligand Interactions by Thermal Shift Assay. Curr. Protoc. Protein Sci. 79, 28.9.1-28.9.14 (2015).

36. D. Benjamin, M. Colombi, C. Moroni, M. N. Hall, Rapamycin passes the torch: a new generation of mTOR inhibitors. Nature Reviews Drug Discovery. 10, 868-880 (2011)

37. H. Yang, D. G. Rudge, J. D. Koos, B. Vaidialingam, H. J. Yang, N. P. Pavletich, mTOR kinase structure, mechanism and regulation. Nature 497, 217-223 (2013).

38. J. R. Wetterau, R. E. Gregg, T. W. Harrity, C. Arbeeny, M. Cap, F. Connolly, C. H. Chu, R. J. George, D. A. Gordon, H. Jamil, K. G. Jolibois, L. K. Kunselman, S. J. Lan, T. J. Maccagnan, B. Ricci, M. Yan, D. Young, Y. Chen, O. M. Fryszman, J. V. Logan, C. L. Musial, M. A. Poss, J. A. Robl, L. M. Simpkins, W. A. Slusarchyk, R. Sulsky, P. Taunk, D. R. Magnin, J. A. Tino, R. M. Lawrence, J. K. Dickson, S. A. BillerWetterau, An MTP inhibitor that normalizes atherogenic lipoprotein levels in WHHL rabbits. Science 282, $751-754$ (1998).

39. D. P. Carbone, M. Reck, L. Paz-Ares, B. Creelan, L. Horn, M. Steins, E. Felip, M. M. van den Heuvel, T. E. Ciuleanu, F. Badin, N. Ready, T. J. N. Hiltermann, S. Nair, R. Juergens, S. Peters, E. Minenza, J. M. Wrangle, D. Rodriguez-Abreu, H. Borghaei, G. R. Blumenschein, Jr., L. C. Villaruz, L. Havel, J. Krejci, J. Corral Jaime, H. Chang, W. J. Geese, P. Bhagavatheeswaran, A. C. Chen, M. A. Socinski, CheckMate 026 Investigators, First-line nivolumab in stage IV or recurrent non-small-cell lung cancer. $N$. Engl. J. Med. 376, 2415-2426 (2017).

40. W. Zou, J. D. Wolchok, L. Chen, PD-L1 (B7-H1) and PD-1 pathway blockade for cancer 
therapy: mechanisms, response biomarkers, and combinations. Sci. Transl. Med. 8, $328 \mathrm{rv} 4$ (2016).

41. S. L. Topalian, F. S. Hodi, J. R. Brahmer, S. N. Gettinger, D. C. Smith, D. F. McDermott, J. D. Powderly, R. D. Carvajal, J. A. Sosman, M. B. Atkins, P. D. Leming, D. R. Spigel, S. J. Antonia, L. Horn, C. G. Drake, D. M. Pardoll, L. Chen, W. H. Sharfman, R. A. Anders, J. M. Taube, T. L. McMiller, H. Xu, A. J. Korman, M. Jure-Kunkel, S. Agrawal, D. McDonald, G. D. Kollia, A. Gupta, J. M. Wigginton, M. Sznol, Safety, activity, and immune correlates of anti-PD-1 antibody in cancer. N. Engl. J. Med. 366, 2443-2454 (2012).

42. N. A. Rizvi, M. D. Hellmann, A. Snyder, P. Kvistborg, V. Makarov, J. J. Havel, W. Lee, J. Yuan, P. Wong, T. S. Ho, M. L. Miller, N. Rekhtman, A. L. Moreira, F. Ibrahim, C. Bruggeman, B. Gasmi, R. Zappasodi, Y. Maeda, C. Sander, E. B. Garon, T. Merghoub, J. D. Wolchok, T. N. Schumacher, T. A. Chan, Cancer immunology. mutational landscape determines sensitivity to PD-1 blockade in non-small cell lung cancer. Science 348, 124$128(2015)$

43. J. M. Pitt, M. Vétizou, R. Daillère, M. P. Roberti, T. Yamazaki, B. Routy, P. Lepage, I. G. Boneca, M. Chamaillard, G. Kroemer, L. Zitvogel, Resistance mechanisms to immunecheckpoint blockade in cancer: tumor-intrinsic and -extrinsic factors. Immunity 44, 1255-1269 (2016).

44. H. Li, X. Li, S. Liu, L. Guo, B. Zhang, J. Zhang, Q. Ye, Programmed cell death-1 (PD-1) checkpoint blockade in combination with a mammalian target of rapamycin inhibitor restrains hepatocellular carcinoma growth induced by hepatoma cell-intrinsic PD-1. 
Hepatology 66, 1920-1933 (2017).

45. A. el Hage, O. Dormond, Combining mTOR inhibitors and $\mathrm{T}$ cell-based immunotherapies in cancer treatment. Cancers 13, 1359 (2021).

46. C. Stefanutti, Lomitapide-a microsomal triglyceride transfer protein inhibitor for homozygous familial hypercholesterolemia. Curr. Atheroscler. Rep. 22, 38(2020).

47. A. Abulizi, D. F. Vatner, Z. Ye, Y. Wang, J. Camporez, D. Zhang, M. Kahn, K. Lyu, A. Sirwi, G. W. Cline, M. Mahmood Hussain, P. Aspichueta, V. T. Samuel, G. I. Shulman, Membrane-bound sn-1,2-diacylglycerols explain the dissociation of hepatic insulin resistance from hepatic steatosis in MTTP knockout mice. J. Lipid Res. 61, 1565-1576 (2020).

48. Y. Xie, H. Matsumoto, I. Nalbantoglu, T. A. Kerr, J. Luo, D. C. Rubin, S. Kennedy, N. O. Davidson, Intestine-specific Mttp deletion increases the severity of experimental colitis and leads to greater tumor burden in a model of colitis associated cancer. PLoS One $\mathbf{8}$, e67819 (2013)

49. Q. Zuo, L. Liao, Z. Yao, Y. Liu, D. Wang, S. Li, X. Yin, Q. He, W. Xu, Targeting PP2A with lomitapide suppresses colorectal tumorigenesis through the activation of AMPK/Beclin1-mediated autophagy. Cancer Letters. 521, 281-293 (2021)

50. V. Voss, C. Senft, V. Lang, M. W. Ronellenfitsch, J. P. Steinbach, V. Seifert, D. Kögel, The pan-Bcl-2 inhibitor (-)-gossypol triggers autophagic cell death in malignant glioma. Mol. Cancer Res. 8, 1002-1016 (2010).

51. L. Gattinoni, C. A. Klebanoff, N. P. Restifo, Pharmacologic induction of CD8+ T cell 
memory: better living through chemistry. Sci Transl Med. 1, 11 ps 12 (2009).

52. C. Zhang, S. Wang, J. Li, W. Zhang, L. Zheng, C. Yang, T. Zhu, R. Rong, The mTOR signal regulates myeloid-derived suppressor cells differentiation and immunosuppressive function in acute kidney injury. Cell Death Dis. 8, e2695 (2017). 


\section{Figure legends}

Fig. 1 Identification of lomitapide as an mTORC1 inhibitor.

a Flowchart of in silico virtual screening. b Structure of lomitapide. c The docking pose of lomitapide within the ATP-binding core of human mTORC1. d, e The thermal denaturation of recombinant mTOR kinase domain was measured in the absence and presence of varying lomitapide concentrations, as indicated. Representative derivative (dF/dT) curves are shown for untreated and treated with varying ligand concentrations (d). Midpoint temperatures of the protein-unfolding transition $(\mathrm{Tm})$ are presented as bars (e). Values are mean $\pm \mathrm{SD}$ of at least three independent measurements $(* P<0.05)$. $\mathbf{f}$ In vitro kinase assays were performed in the absence or presence of lomitapide using mTOR immunoprecipitates prepared from HEK293T cell lysates. mTORC1 kinase activity was assessed via immunoblotting of T389 S6K1 phosphorylation. g mTORC2 kinase activity was assessed based on S473 Akt phosphorylation. h In vitro mTORC1 activity assayed in the presence of $50 \mu \mathrm{M}$ lomitapide and increasing concentrations of ATP. T389 phosphorylation of S6K1 was measured via immunoblotting.

Fig. 2 Lomitapide inhibits cancer cell viability and reduces mTOR signaling.

a Cancer-specific growth inhibition of lomitapide on HCT116 colorectal cancer cell line. b colony formation of vehicle or lomitapide-treated were measured in HT29, HCT116, and SW480 CRC cells. c mTOR downstream signaling defects in CRC cells were analyzed by immunoblotting treated with vehicle or lomitapide for $24 \mathrm{~h}$ at indicated concentration. The mTOR inhibitor Torin1 was used as control. d S757 phosphorylation of ULK1 and LC3 levels were measured by immunoblotting to assess autophagy induction. 
Fig. 3 Lomitapide leads to autophagic cancer cell death.

a Significantly enriched pathways in lomitapide-treated HCT116 cells compared with vehicletreated cells identified through KEEG analysis. b Volcano plot showing significant gene expression changes in response to lomitapide treatment in HCT116 cells. c HT29 cells were transfected with GFP-LC3 plasmid for $24 \mathrm{~h}$, and treated with $5 \mu \mathrm{M}$ lomitapide for another $24 \mathrm{~h}$. GFP-LC3 puncta was visualized by confocal microscope. Scale bar: $20 \mu \mathrm{m}$. d Cell viability was measured in HT29 cells treated with $5 \mu \mathrm{M}$ lomitapide in the absence or presence of $100 \mathrm{nM}$ bafilomycin for $24 \mathrm{~h}$. e HT29 cells treated with $5 \mu \mathrm{M}$ lomitapide in the absence or presence of 1 mM 3-MA for $24 \mathrm{~h}$. LC3 levels were measured by immunoblotting to assess autophagy induction. f si-control and si-ATG7-transfected HT29 cells were treated with $5 \mu \mathrm{M}$ lomitapide for $24 \mathrm{~h}$. LC3 levels were measured by immunoblotting to assess autophagy induction.

\section{Fig. 4 Lomitapide suppresses the growth of tumor xenografts.}

a HT29 cells were inoculated into flanks of nude mice and tumor volumes were measured for 10 days after intraperitoneal injection into xenograft tumors every 2 days. b Representative images of xenograft tumors at the day of sacrifice. c Body weight of xenograft mice bearing HT29 tumors during the in vivo experiment. Data are expressed as means \pm SEM $(* P<0.05 ; * * P<$ $0.01 ; * * * P<0.001$, Student's $t$ test). ( $n=6$ per group). d Hematoxylin and eosin (H\&E) staining of tumor tissues collected from either vehicle or lomitapide treated mice. e Tumor tissues were subjected to immunohistochemistry staining with Ki67 antibodies. Scale bar: $20 \mu \mathrm{m}$. 
Fig. 5 Lomitapide suppresses growth of patient-derived CRC organoids.

a Dose-response curves of patient-derived CRC organoids CRC-01 (KRAS ${ }^{\mathrm{WT}}$; APC and TP53 mutant) and CRC-02 (KRAS ${ }^{\mathrm{G} 12 \mathrm{~V}}$; APC and TP53 mutant) treated with $10 \mu \mathrm{M}$ 5-FU or $10 \mu \mathrm{M}$ lomitapide. Organoid size was measured and quantified at $48 \mathrm{~h}$ of either 5-FU or lomitapide treatment relative to vehicle control. b Dose-response images of patient-derived CRC organoids CRC-01 and CRC-02 treated with DMSO, lomitapide, or 5-FU for $72 \mathrm{~h}$ at indicated concentrations. Organoids were stained with CFSE as an organoid marker (blue) and PI as a dead cell marker (red). Scale bars: $2 \mathrm{~mm}$ for CRC-01 and $1 \mathrm{~mm}$ for CRC-02. c H\&E staining of the original matrigel CRC-01 organoid culture. Scale bar: $1 \mathrm{~mm}$. d LC3 levels were measured by immunoblotting to assess autophagy induction. Lysates were prepared from organoids treated with vehicle, $10 \mu \mathrm{M}$ lomitapide, or $10 \mu \mathrm{M}$ 5-FU for $48 \mathrm{~h}$.

Fig. 6 Treatment of tumor-bearing mice with lomitapide improves the therapeutic benefit of anti-PD-1 immunotherapy.

a Tumor growth curves of MC38 mouse colon cancer cells in mice treated with control (vehicle) or lomitapide combined with either control isotype or anti-PD-1. Lomitapide at $20 \mathrm{mg} / \mathrm{kg}$ every day, anti PD-1 or isotype $\operatorname{IgG} 10 \mathrm{mg} / \mathrm{kg}$ every other day. Statistically significant differences (indicated by asterisks) are calculated using an unpaired two-tailed Student's $t$ test $(* P<0.05$, $* * P<0.005$, and $* * * P<0.0005)$. b Representative images of tumor tissues at 18 days following inoculation of MC38 cells. c Representative results of immunofluorescence staining of CD8 (green), PD-L1 (red), and DAPI (blue) in MC38 tumor tissues. Scale bar: $20 \mu \mathrm{m}$. 


\section{Fig. 1}

a

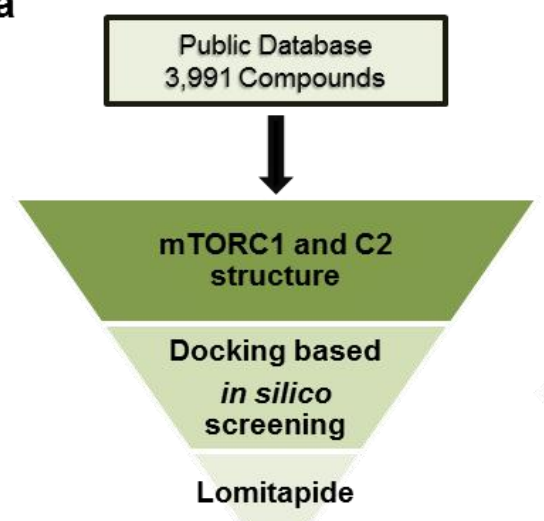

d

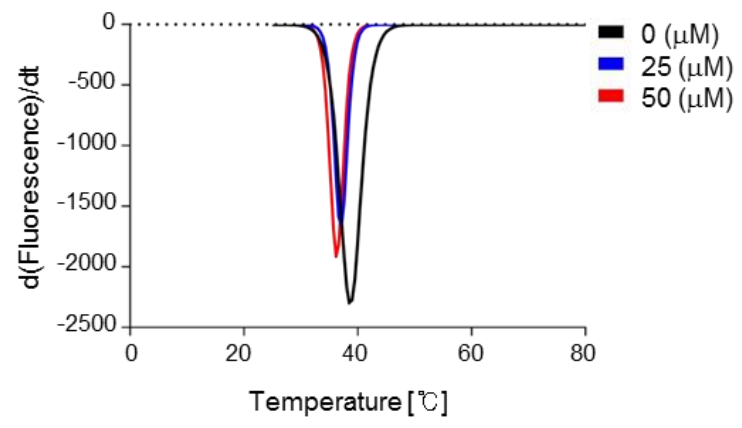

f

IP: mTOR

in vitro kinase assay $\mathrm{C} 1$

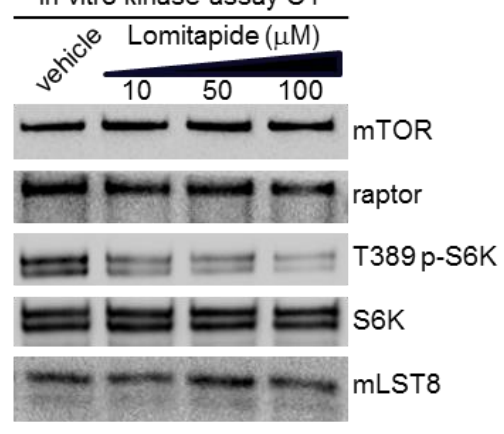

g

in vitro kinase assay $\mathrm{C} 2$

$\nu^{e^{j i 0^{j 0}}} \frac{\text { Lomitapide }(\mu \mathrm{M})}{10 \quad 50 \quad 100}$

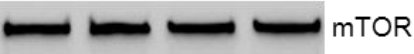

$=0$

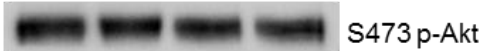

$m=0$ Akt

$=-m$ mLST8
C

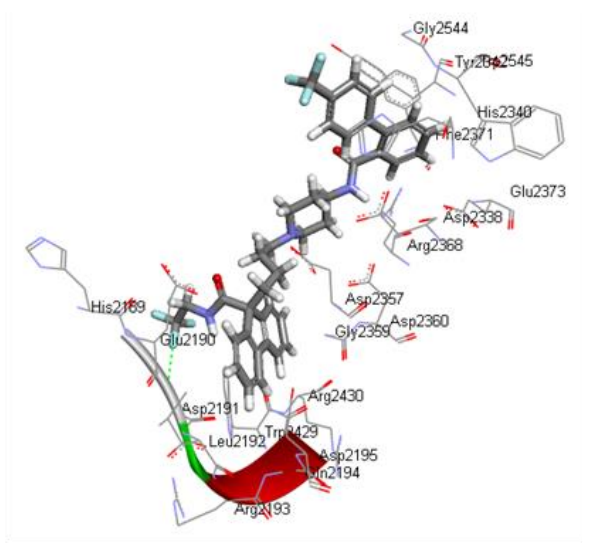

e

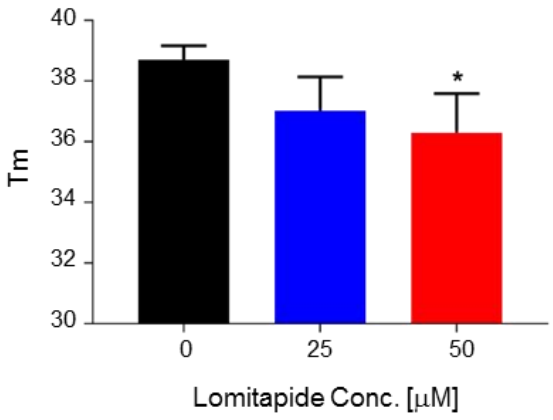

h

IP: MTOR

in vitro kinase assay $\mathrm{C} 1$

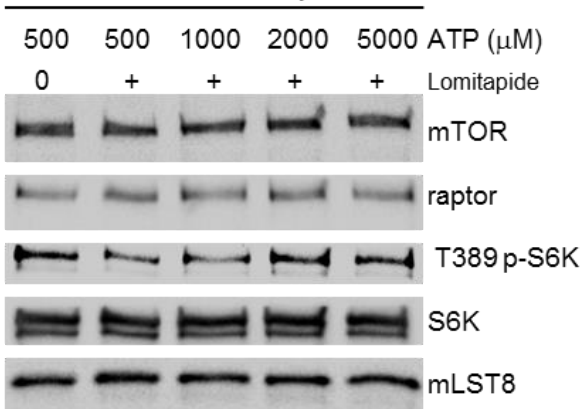


Fig. 2

a

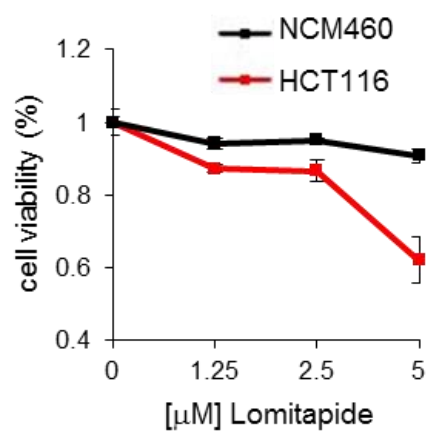

b

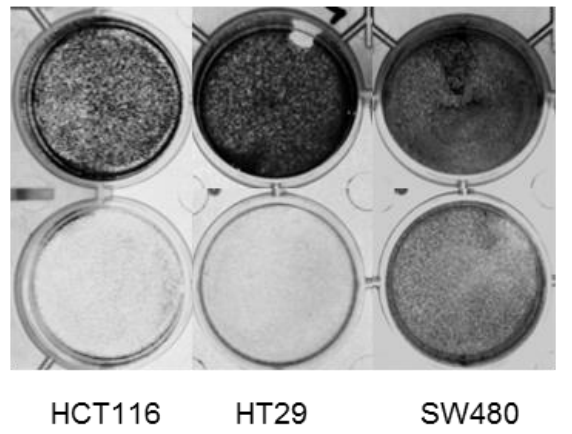

vehicle

Lomitapide $(5 \mu \mathrm{M})$

C
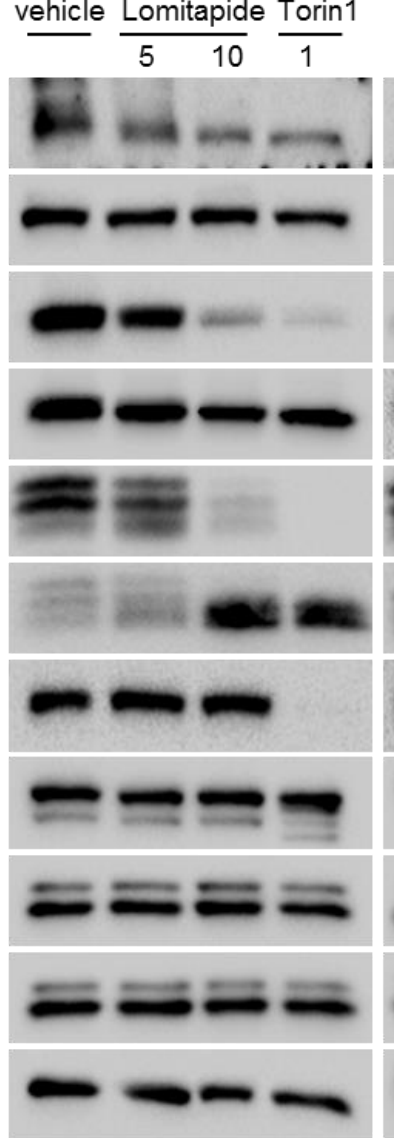

HT29

d

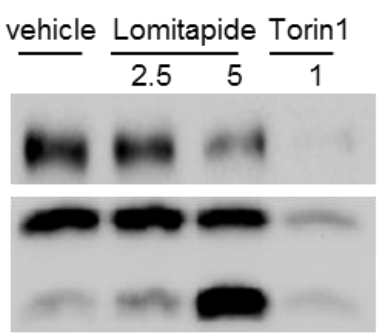

HCT116 $\underline{\text { vehicle Lomitapide Torin1 vehicle Lomitapide Torin1 }} \frac{\text { Lo }}{510} \frac{10}{1}$
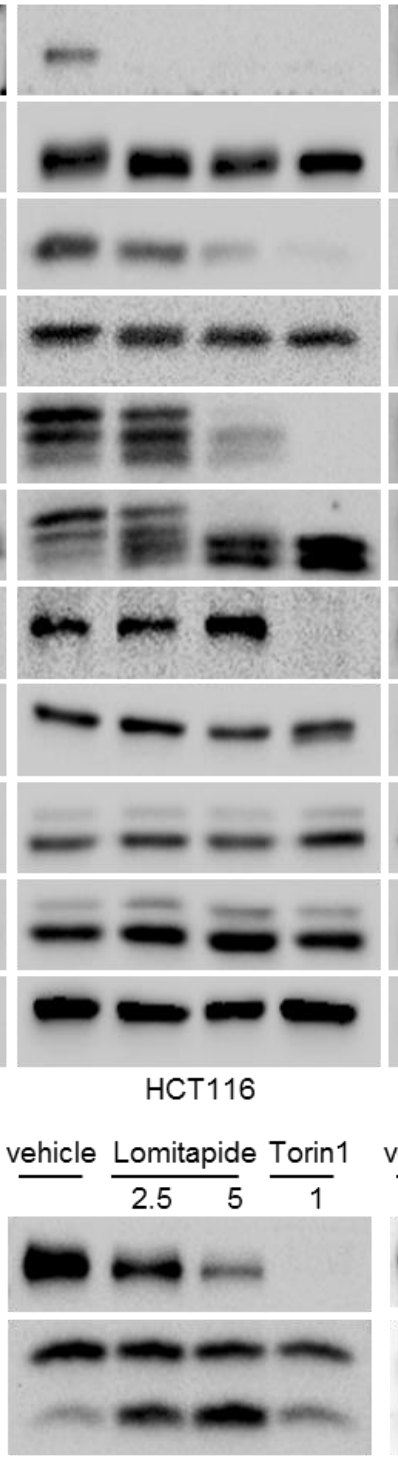

HT29
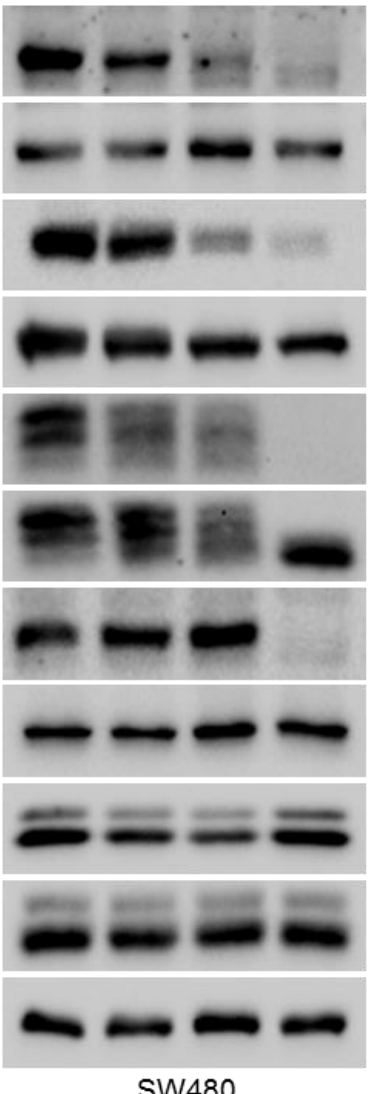

SW480

$\mu \mathrm{M}$

p-S6K

S6K

p-S6

S6

p-4E-BP1

4E-BP1

p-Akt

Akt

p-ERK

ERK

$\alpha$-tubulin

$\underline{\text { vehicle Lomitapide Torin1 }} \frac{\text { MM }}{2.55} \frac{1}{1}$

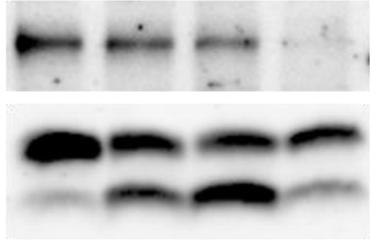

S757 p-Ulk1

LC3 I

LC3 II 
Fig. 3

a
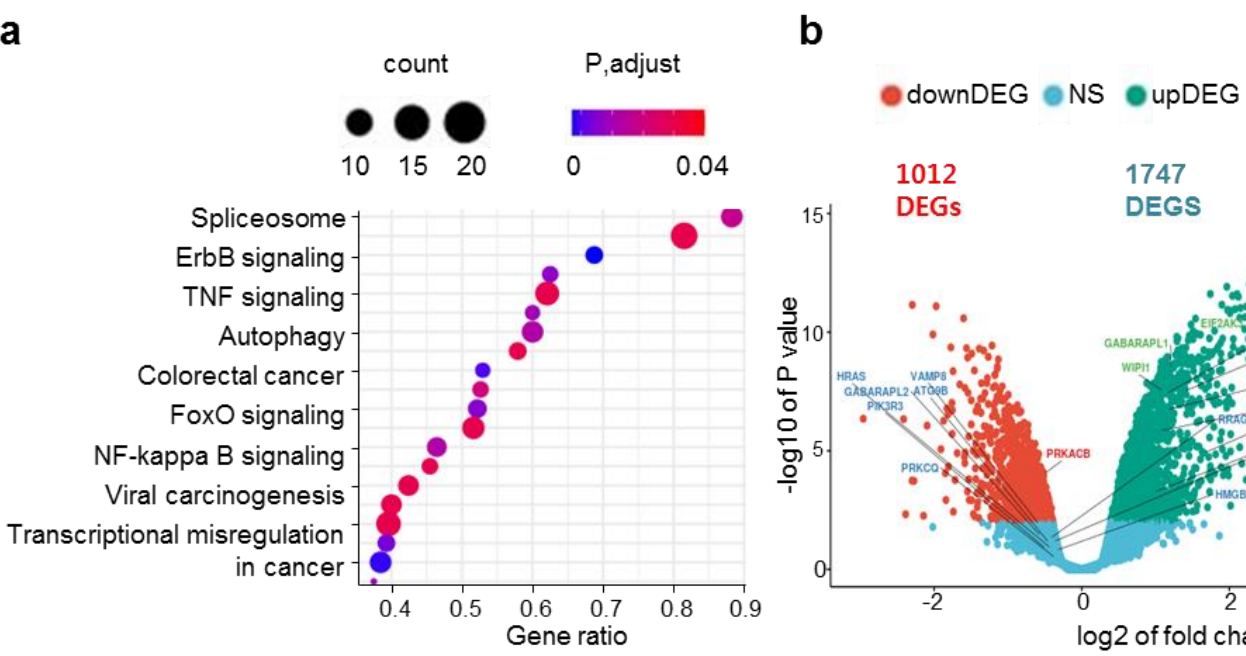

C

DAPI

GFP-LC3
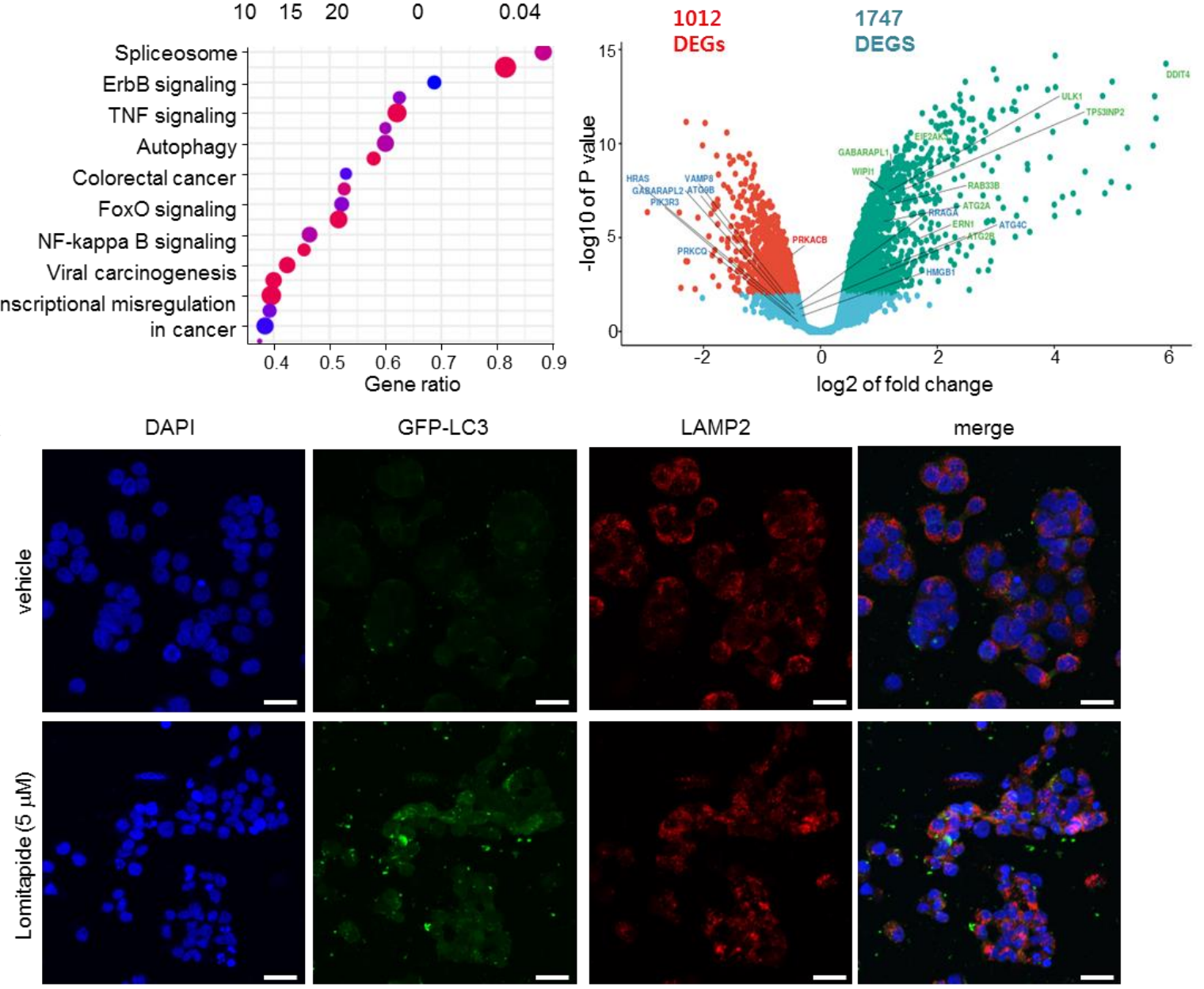

d

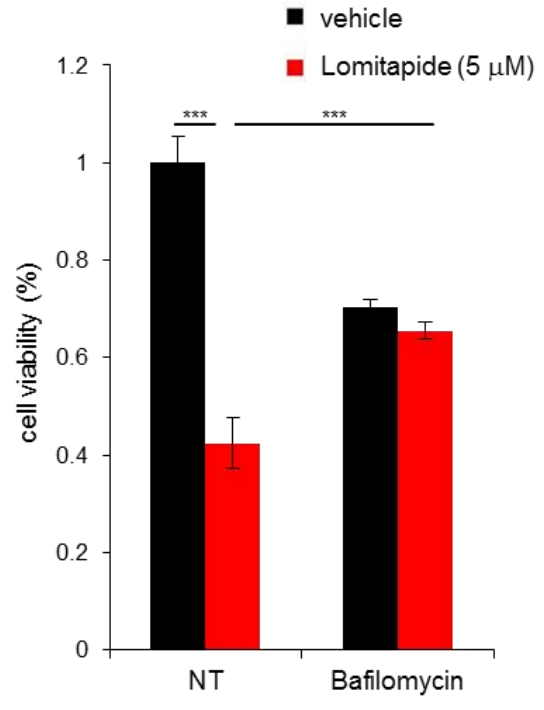

e

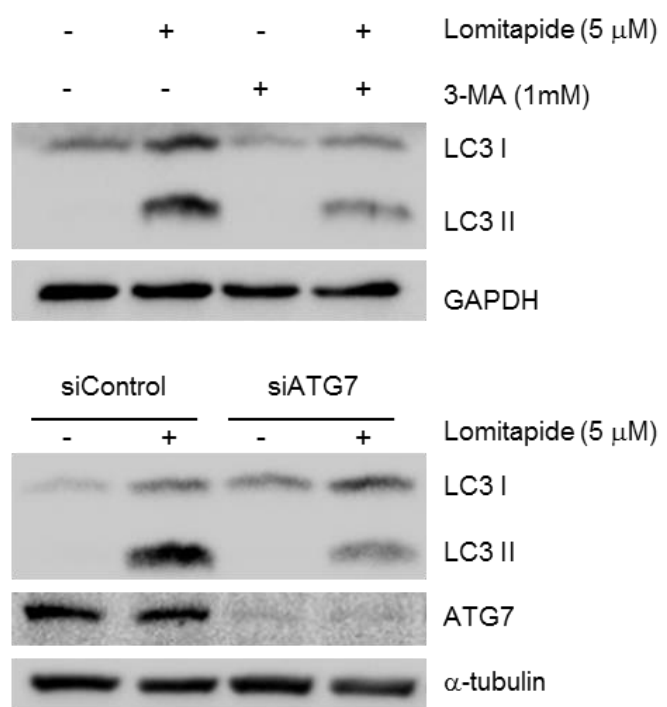


Fig. 4

a

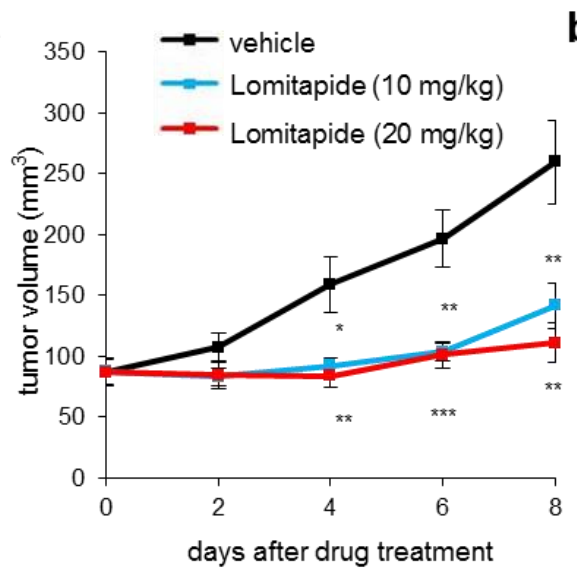

d

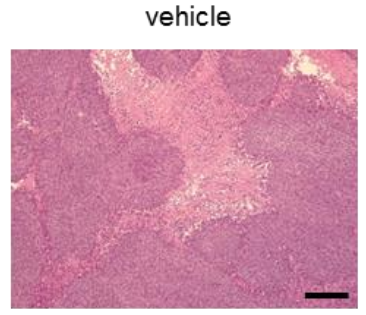

b

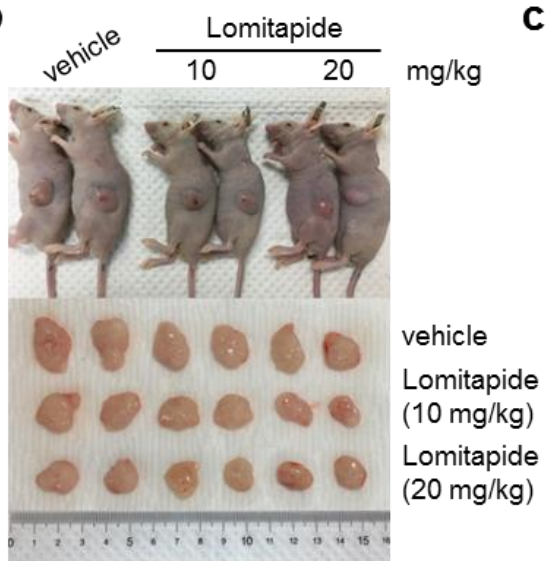

Lomitapide $(20 \mathrm{mg} / \mathrm{kg})$

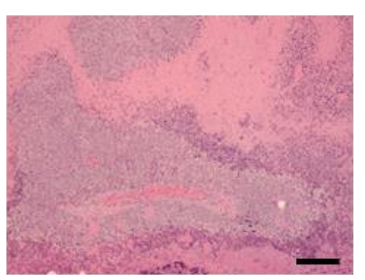

C

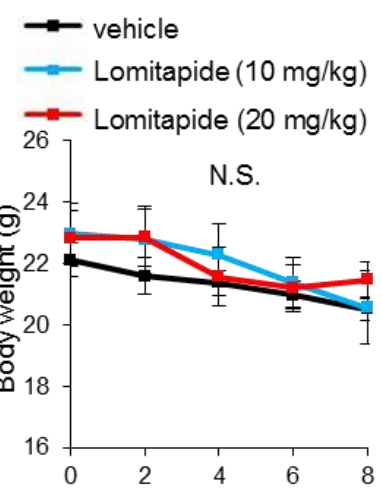

days after drug treatment

e

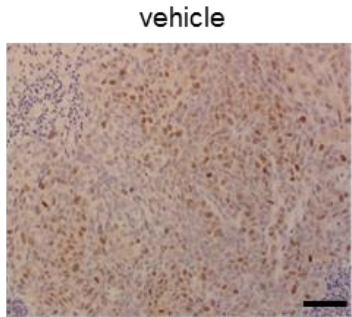

Lomitapide $(20 \mathrm{mg} / \mathrm{kg})$

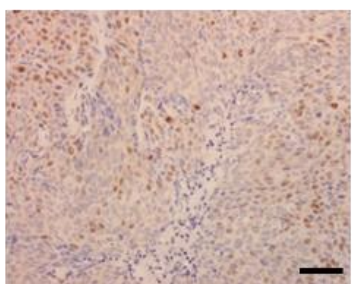


Fig. 5

a
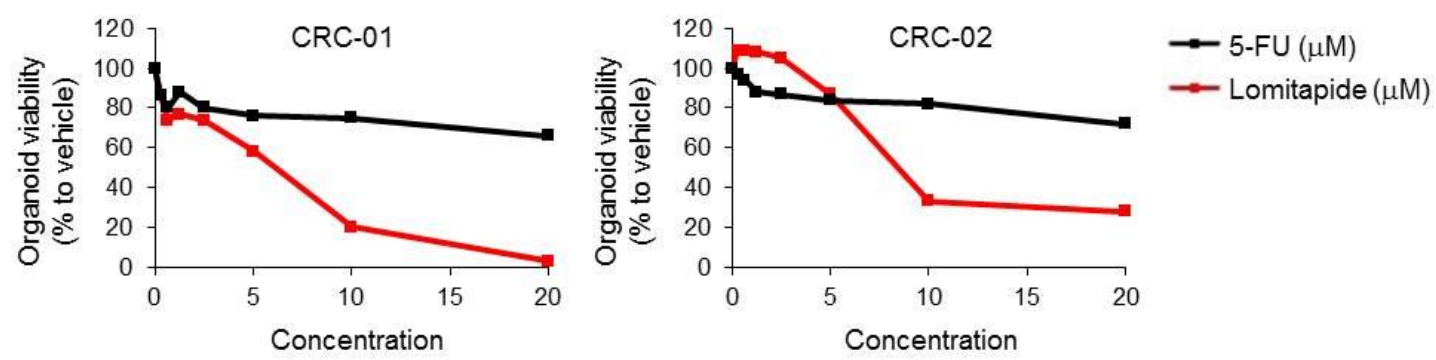

b
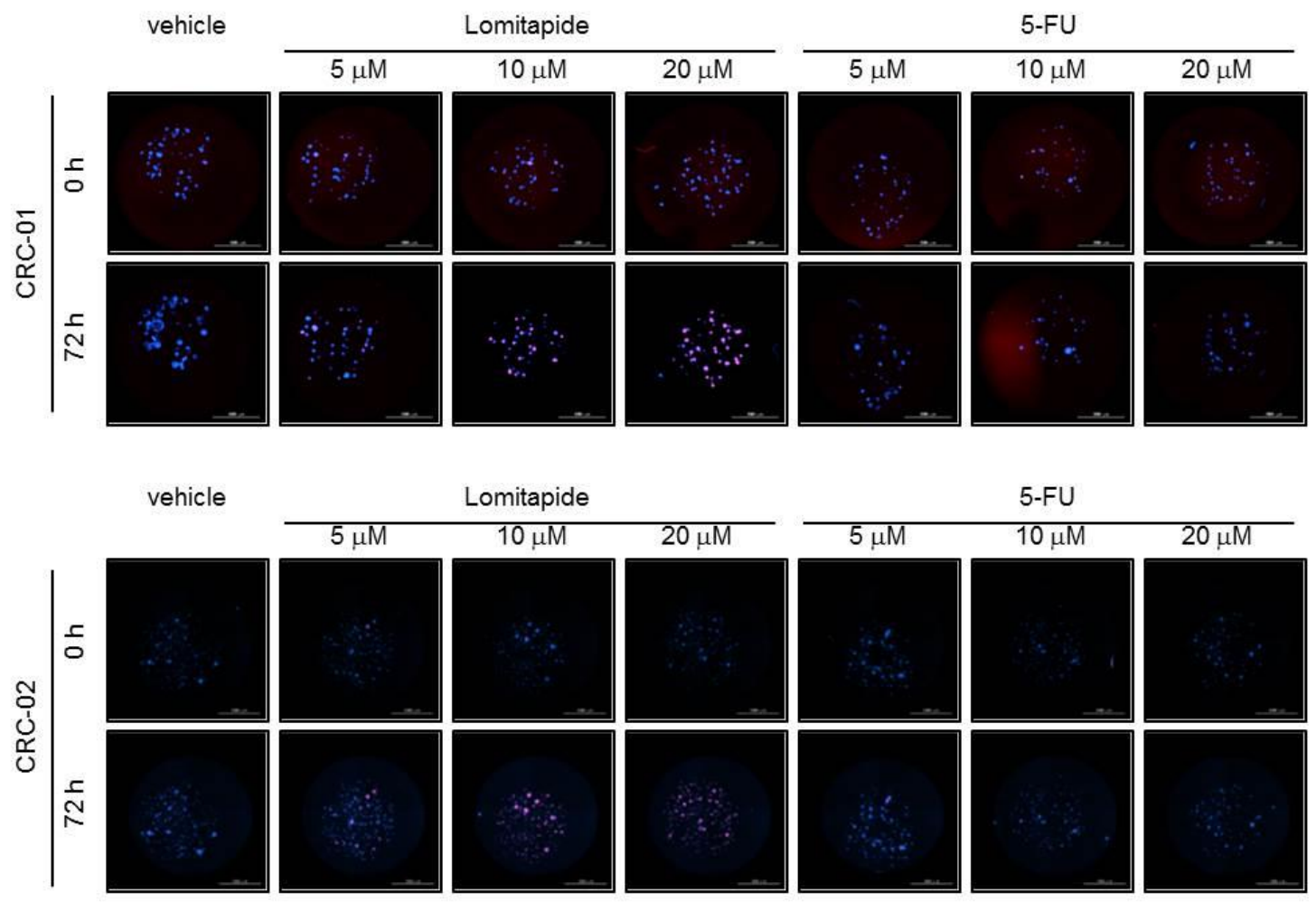

Lomitapide

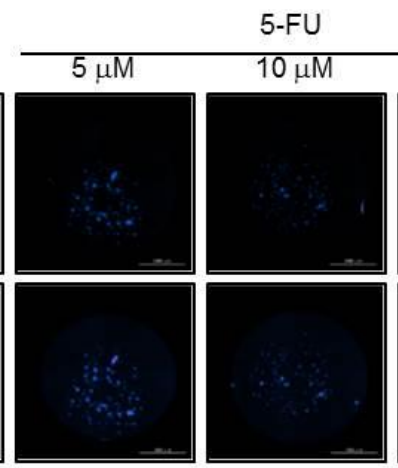

$20 \mu \mathrm{M}$

C

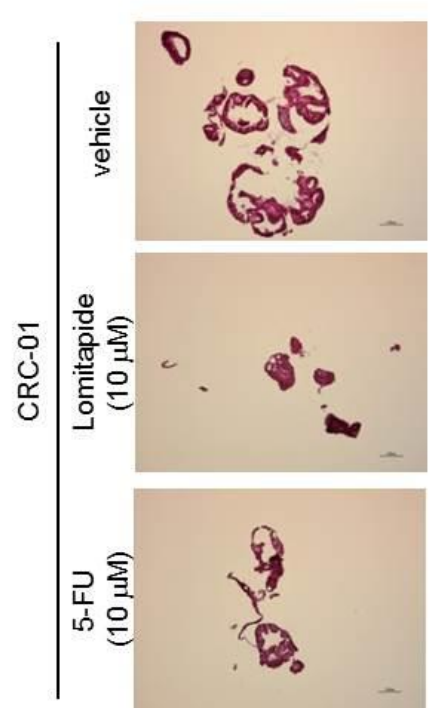

d
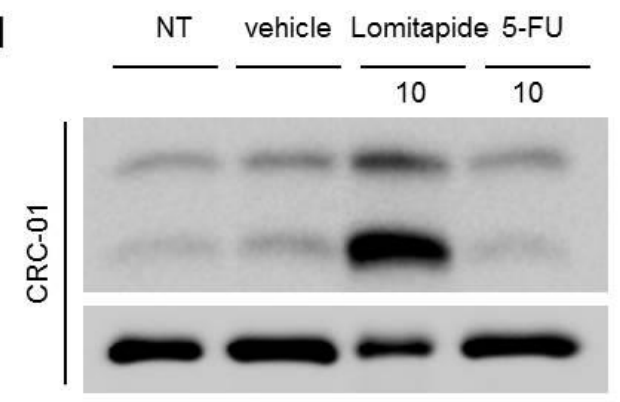

$\mu \mathrm{M}$

LC3I

LC3II

$\alpha$-tubulin

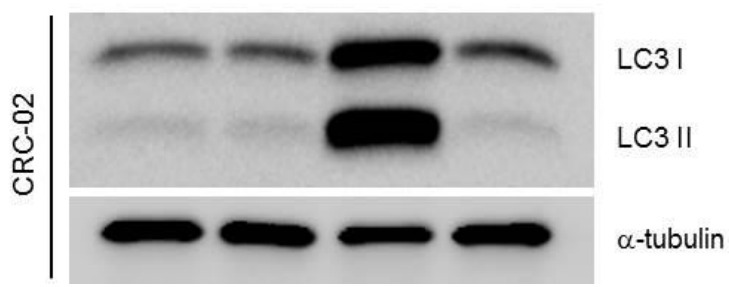


Fig. 6

a

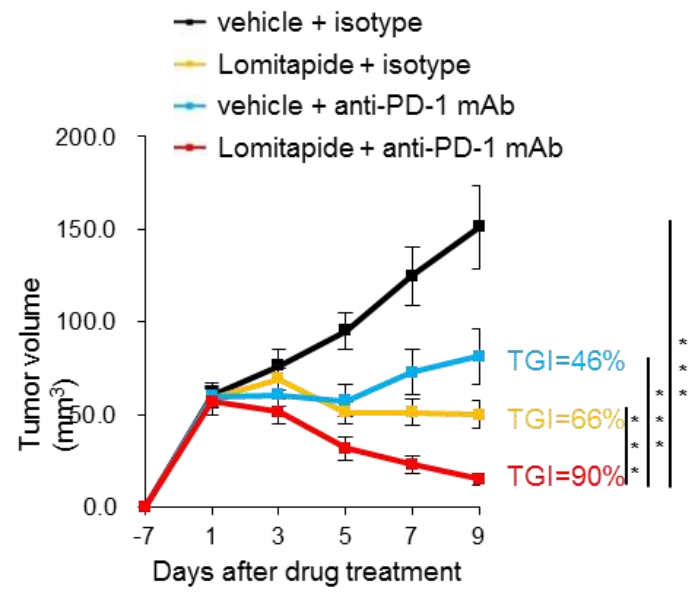

b
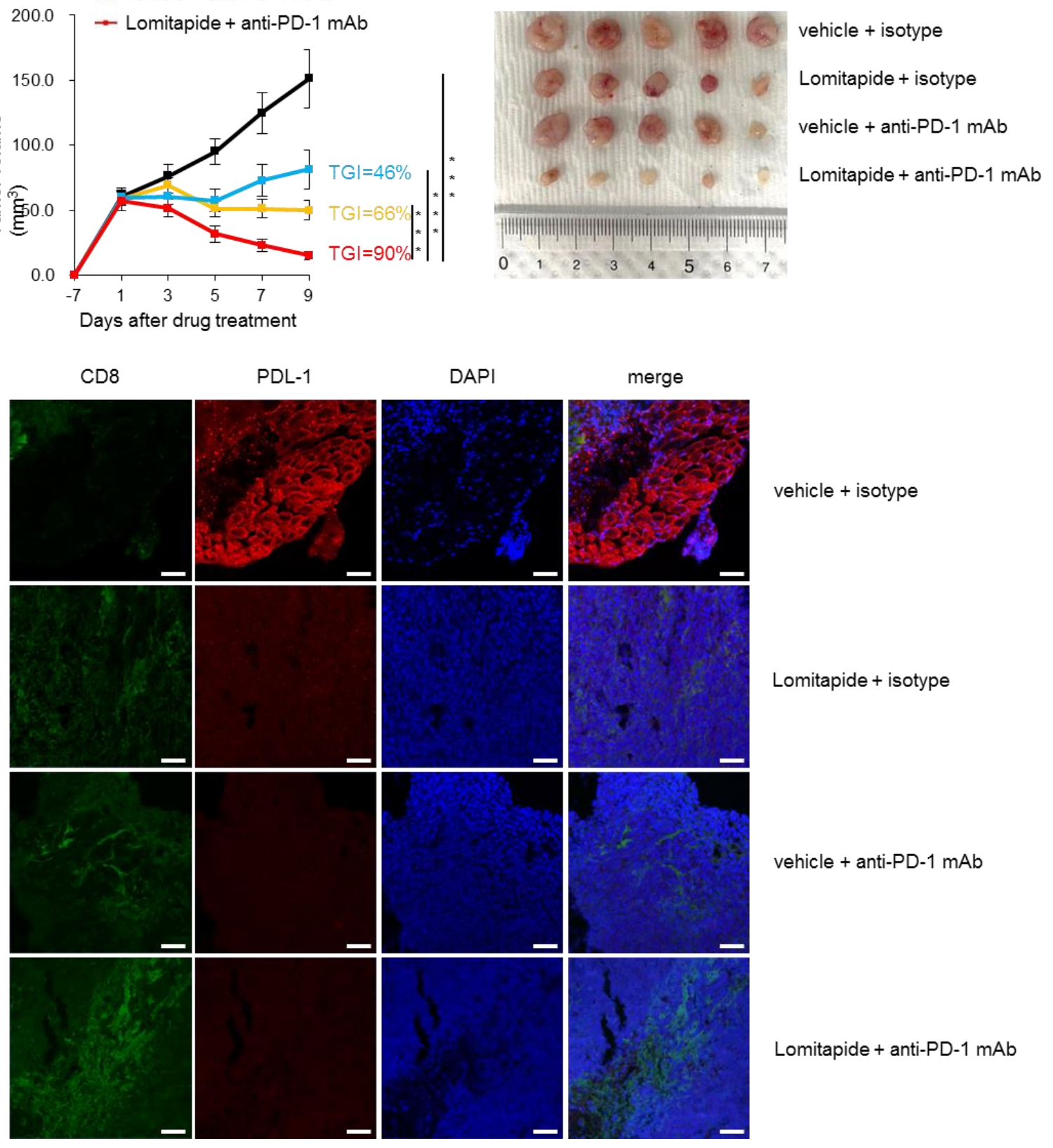


\section{Supplementary information Supplementary Figure 1}

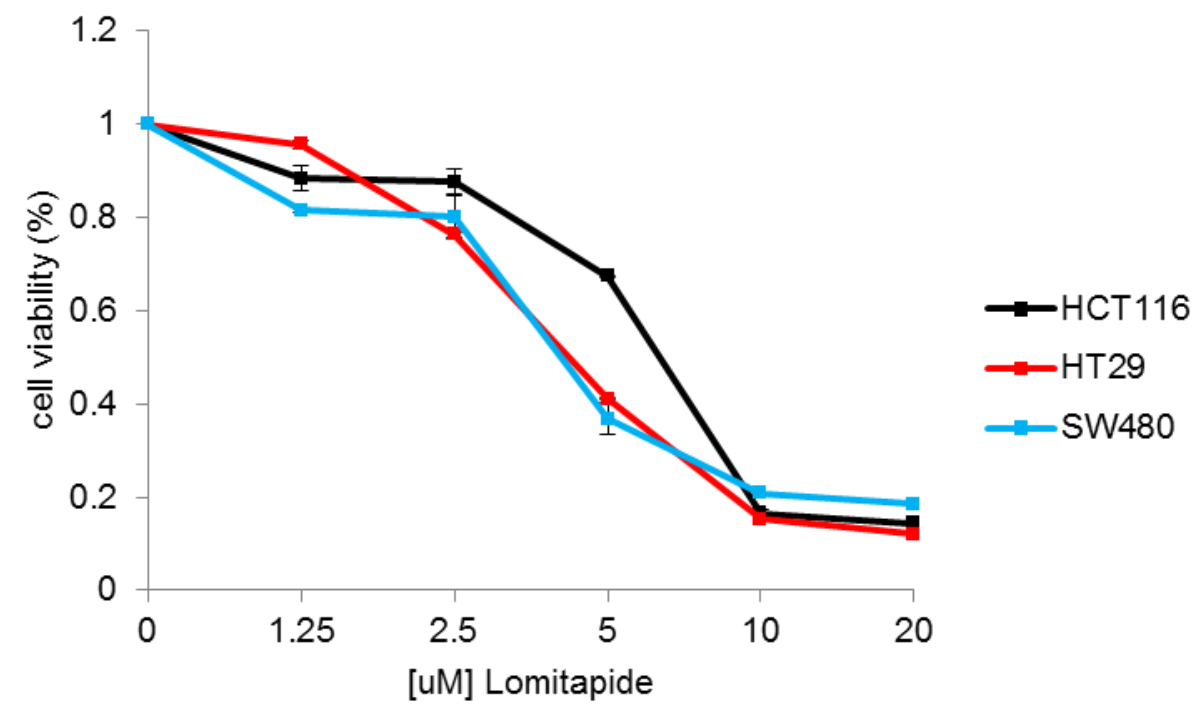

\section{Supplementary Figure 1}

HCT116, HT29, and SW480 CRC cells were treated with lomitapide for $24 \mathrm{~h}$ and cell viability was measured. 


\section{Supplementary Figure 2}

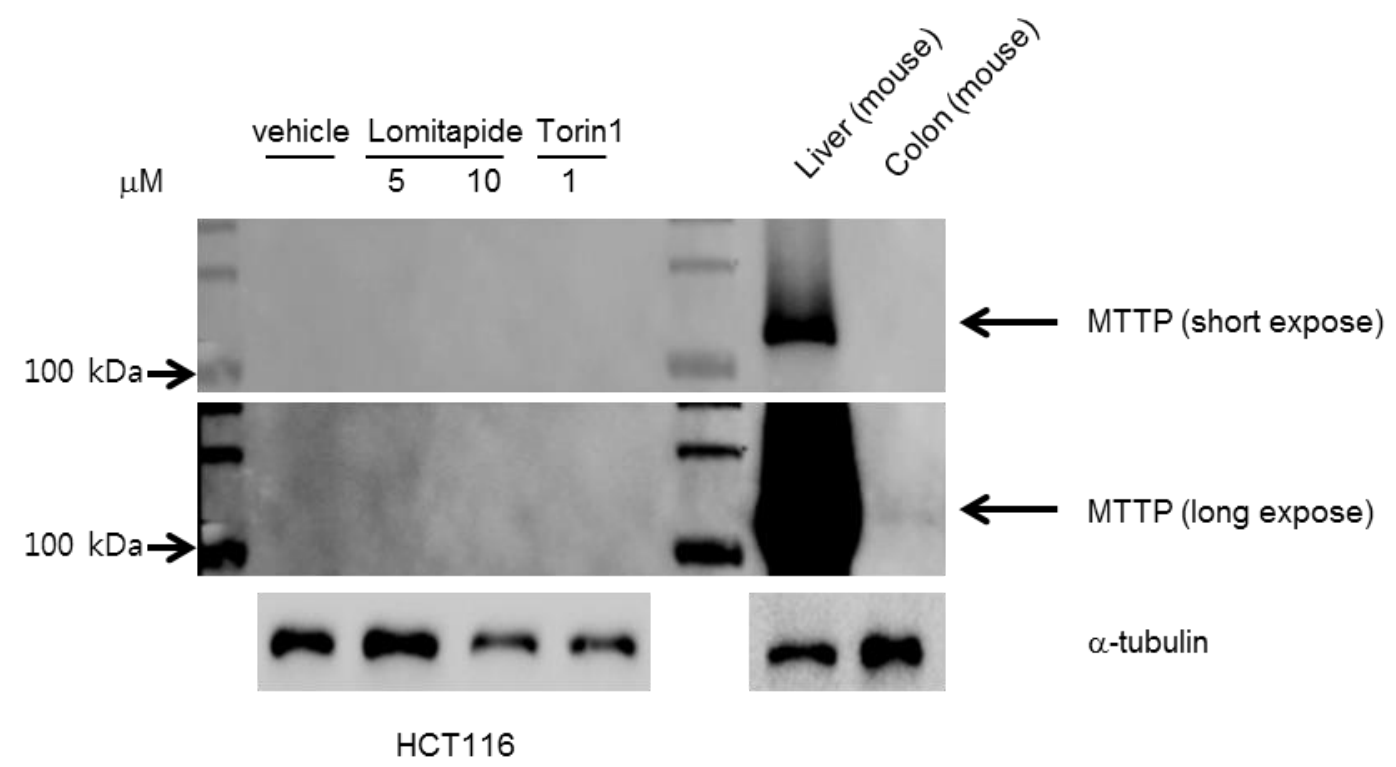

\section{Supplementary Figure 2}

Expression of MTTP in HCT116 CRC cells and mouse tissue lysates (liver and colon) was measured by immunoblotting. 


\section{Supplementary Figure 3}

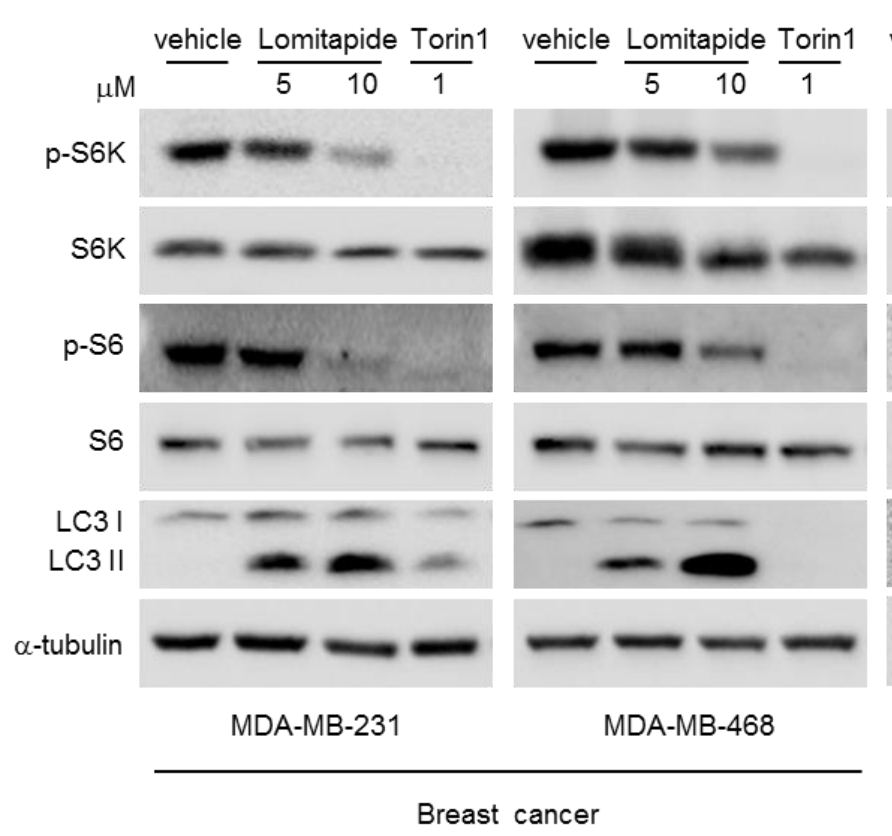

vehicle Lomitapide Torin1 vehicle Lomitapide Torin1

Breast cancer

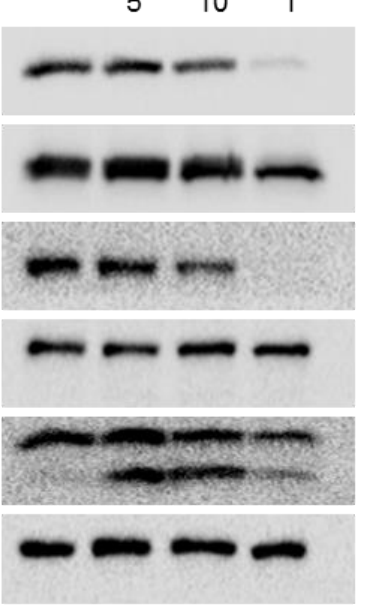

A375

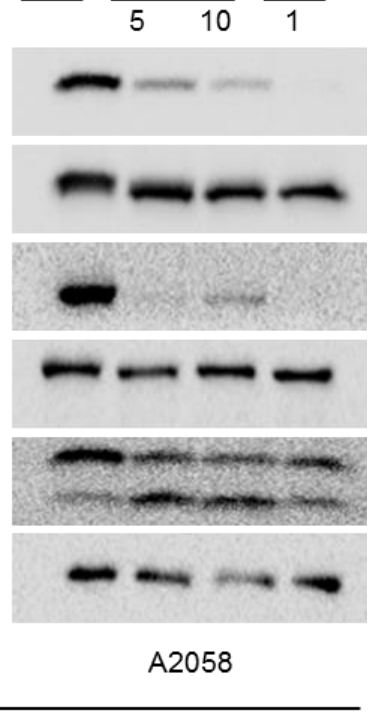

Skin cancer

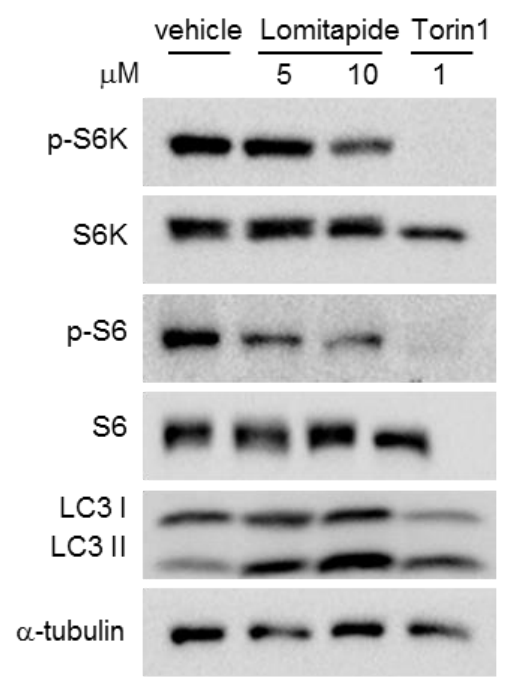

HS746T vehicle Lomitapide Torin1

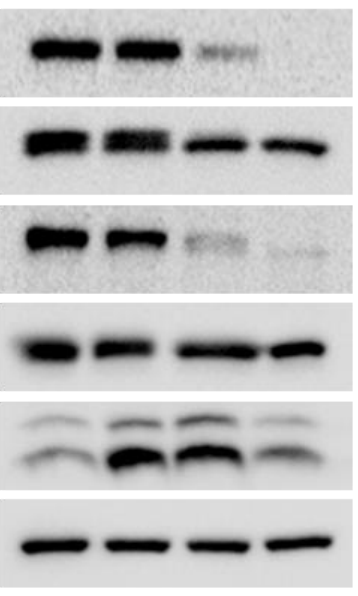

SNU1
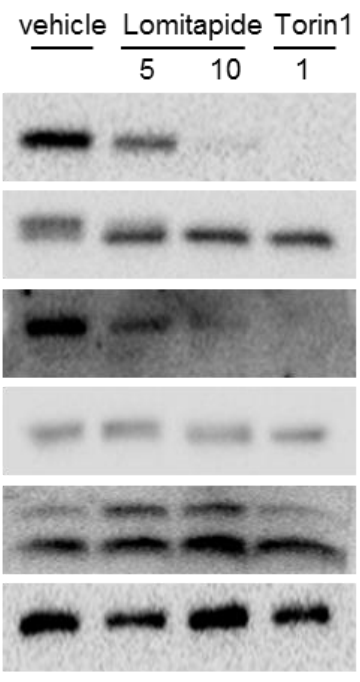

SNU216

Stomach cancer

\section{Supplementary Figure 3}

mTORC1 signaling changes and autophagy induction in various human cancer cells were measured by immunoblotting. $4 \mathrm{~h}$ of lomitapide treatment at indicated concentrations. 


\section{Supplementary Figure 4}

a
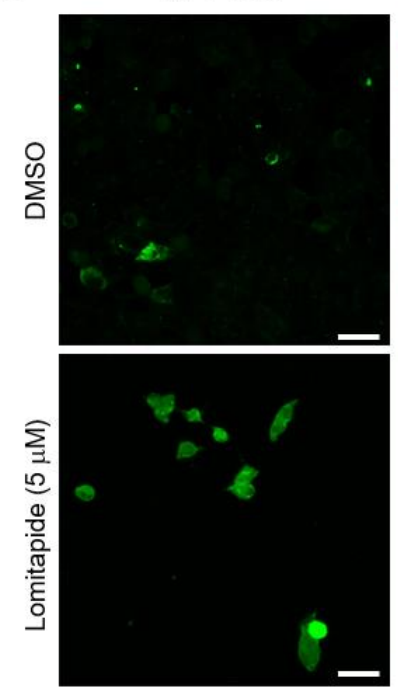

b

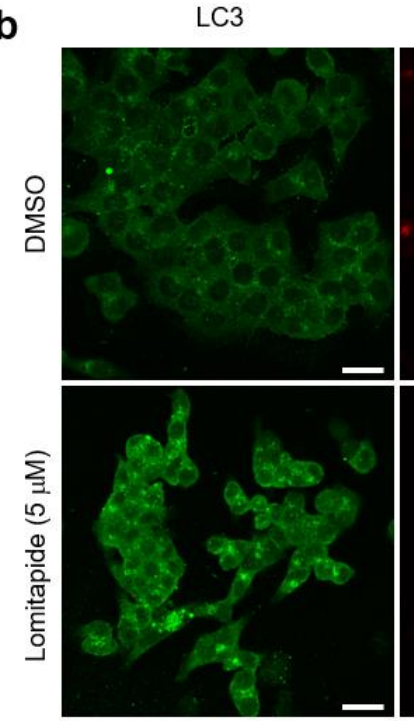

d
LAMP2
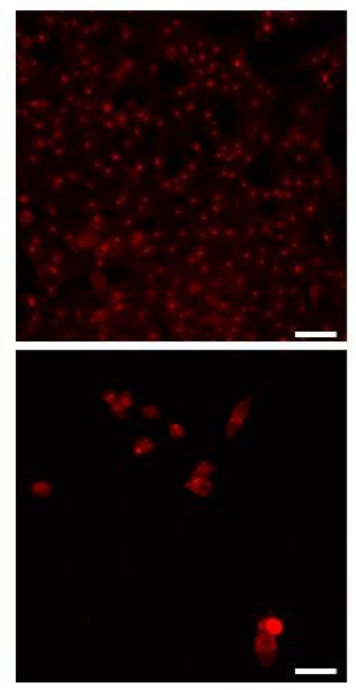

LAMP2

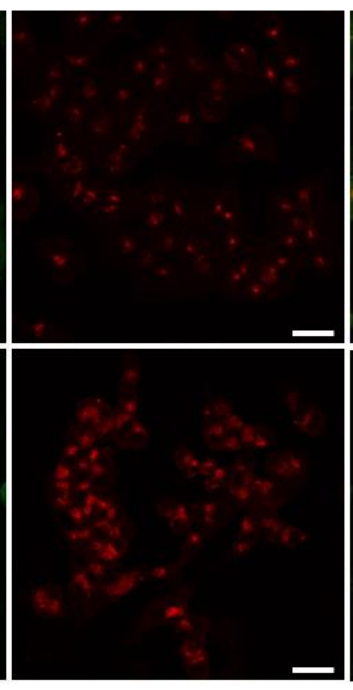

e
DAPI
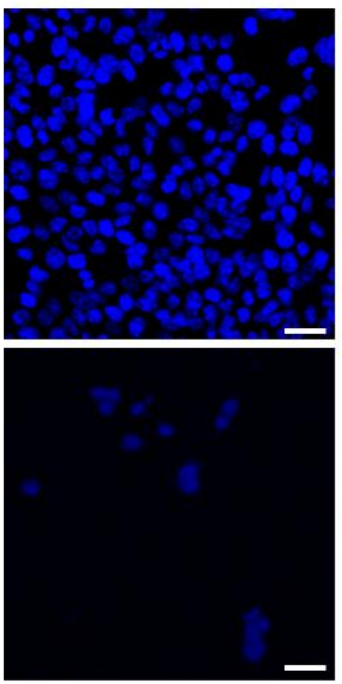

merge

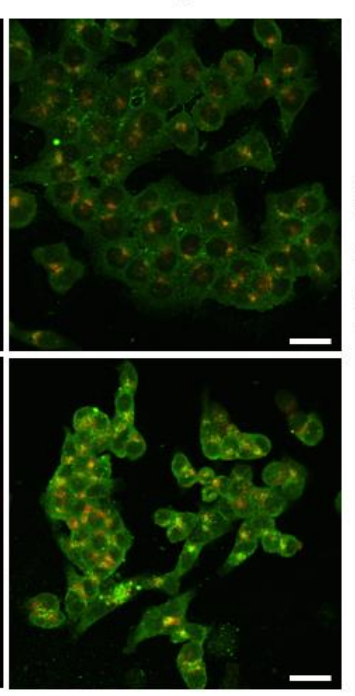

$\alpha$-tubulin

Lomitapide $(5 \mu \mathrm{M})$ 3-MA (1 mM)

LC3 I

LC3 II

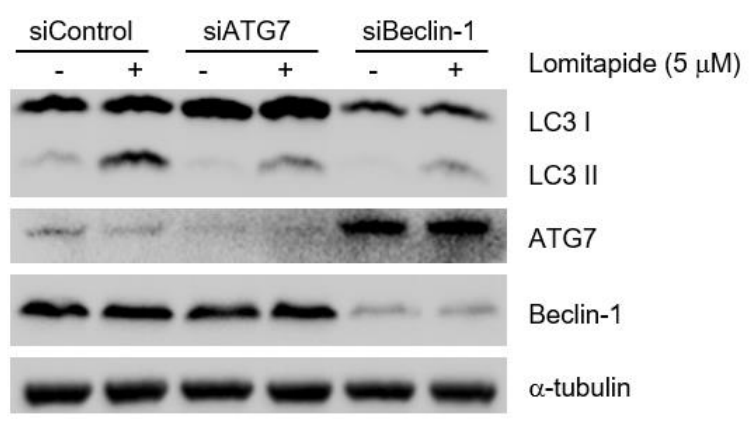




\section{Supplementary Figure 4}

a HCT116 cells were transfected with GFP-LC3 plasmid for $24 \mathrm{~h}$, and treated with $5 \mu \mathrm{M}$ lomitapide for another $24 \mathrm{~h}$. GFP-LC3 puncta was visualized by confocal microscope. Scale bar: $20 \mathrm{~mm}$. b Endogenous LC3B level was detected in HCT116 cells by anti-LC3B antibody under 5 $\mu \mathrm{M}$ lomitapide for $24 \mathrm{~h}$ treatment. Scale bar: $20 \mathrm{~mm}$. c Cell viability was measured in HCT116 cells treated with $5 \mu \mathrm{M}$ lomitapide in the absence or presence of $1 \mathrm{mM} 3-\mathrm{MA}$ for $24 \mathrm{~h}$. d LC3 levels were measured by immunoblotting to assess autophagy induction. HCT116 cells treated with $5 \mu \mathrm{M}$ lomitapide in the absence or presence of $1 \mathrm{mM} 3-\mathrm{MA}$ for $24 \mathrm{~h}$. e si-control, si-ATG7, and si-Beclin-1-transfected HCT116 cells were treated with $5 \mu \mathrm{M}$ lomitapide for $24 \mathrm{~h}$. LC3 levels were measured by immunoblotting to assess autophagy induction. 


\section{Supplementary Figure 5}

HT29

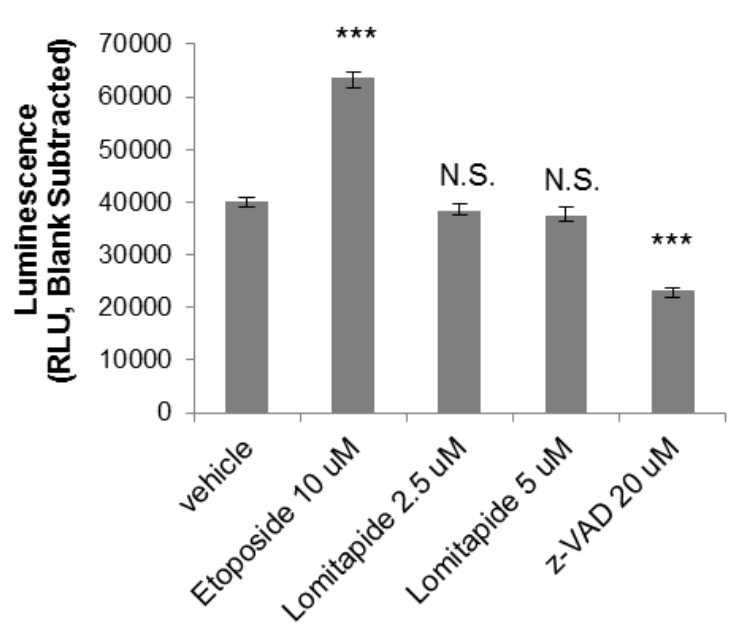

HCT116

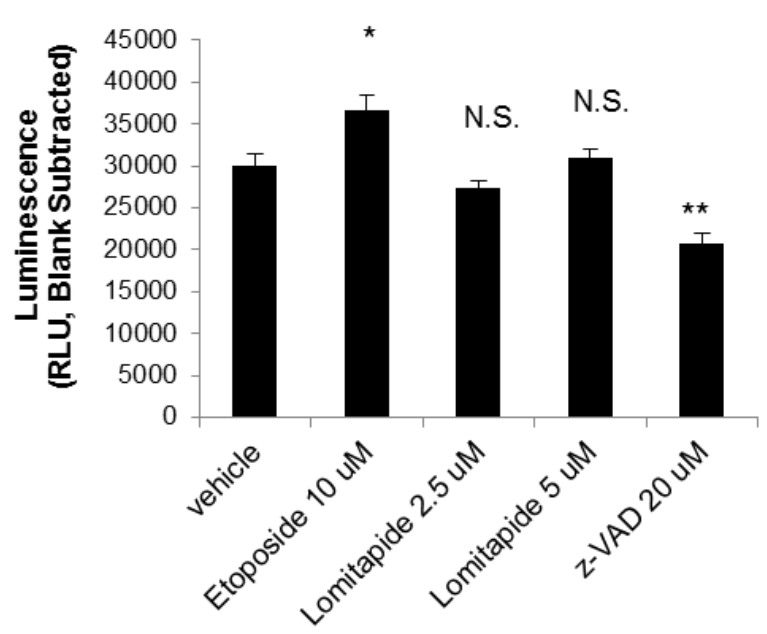

\section{Supplementary Figure 5}

Caspase activity was measured from HT29 and HCT116 cells treated with lomitapide. etoposide, and $\mathrm{z}-\mathrm{VAD}$ for $24 \mathrm{~h}$. Data are expressed as means $\pm \mathrm{SEM}\left({ }^{*} P<0.05\right.$; $* * P<0.01 ; * * * P 0.001$, Student's $t$ test). Etoposide was used as control for the induction of apoptosis. z-VAD was used as control for the inhibition of apoptosis. 


\section{Supplementary Figure 6}
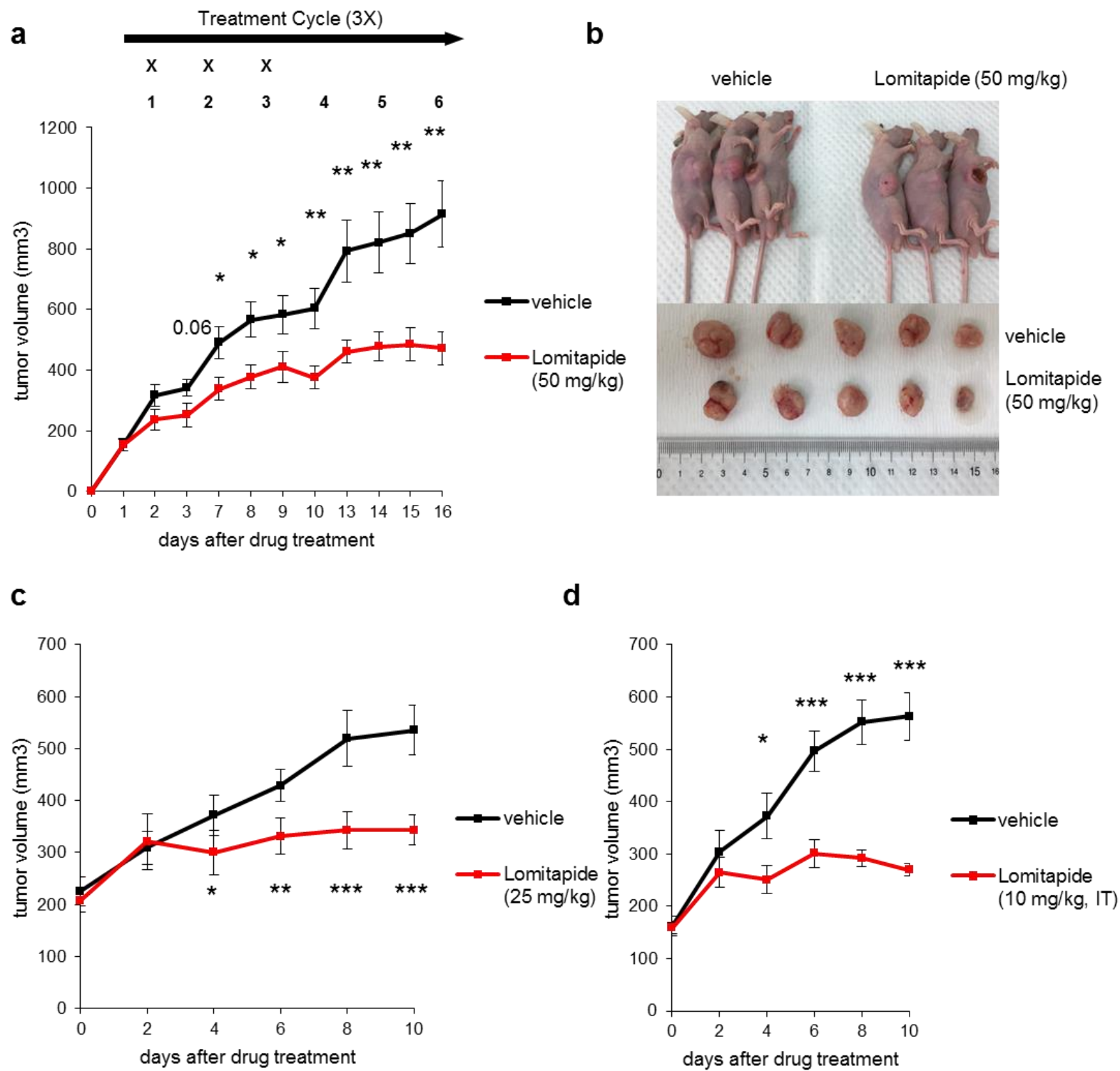

\section{Supplementary Figure 6}

a, b, Nude mice bearing HCT116 xenografts were intraperitoneally treated with lomitapide (50 $\mathrm{mg} / \mathrm{kg}$ ) or vehicle. Tumor volumes were calculated and presented as growth curves (a). Representative tumor tissues resected from mice on day 18 after treatment (b). c, d, HCT116 cells were inoculated into flanks of nude mice ( $\mathrm{n}=6$ per group) and tumor volumes were measured for 10 days after intraperitoneal (c) or intratumoral (d) injection of lomitapide as indicated every 2 days. Data are expressed as means $\pm \mathrm{SEM}(* P<0.05 ; * * P<0.01 ; * * * P<$ 0.001 , Student's $t$ test). 


\section{Supplementary Figure 7}

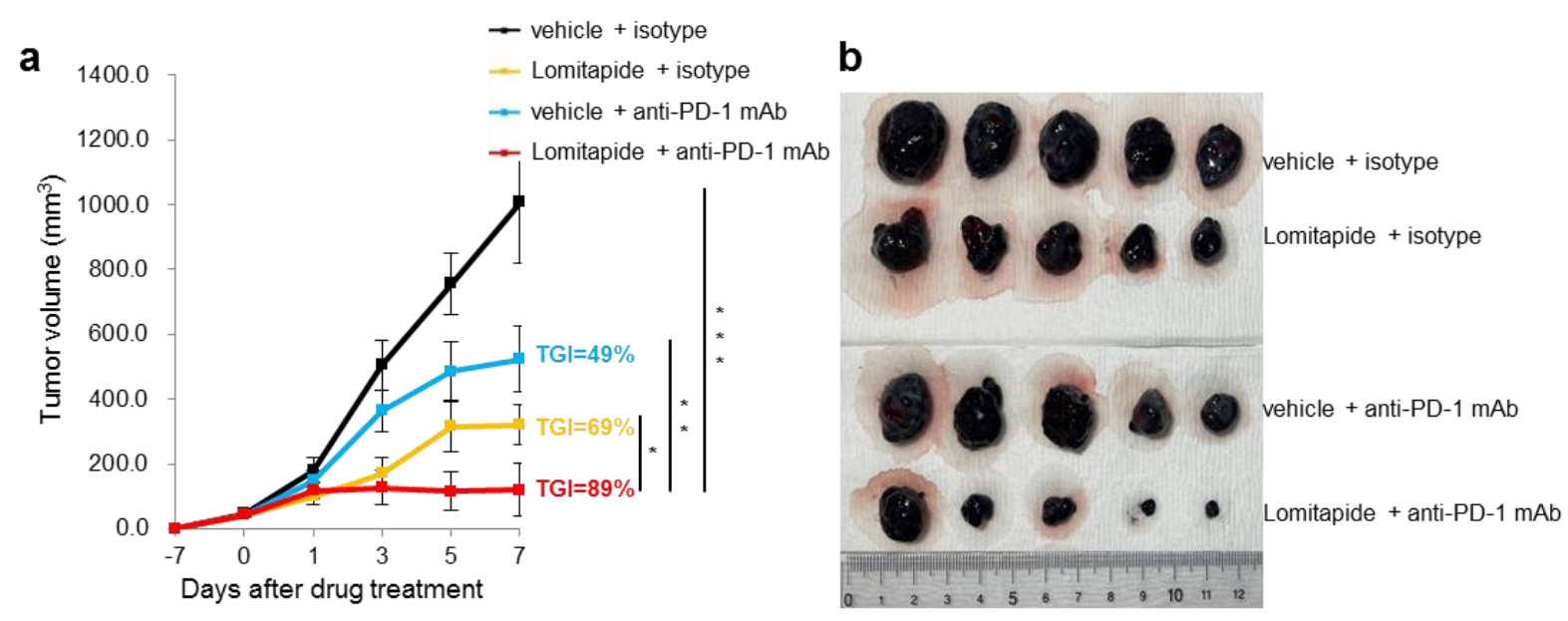

c
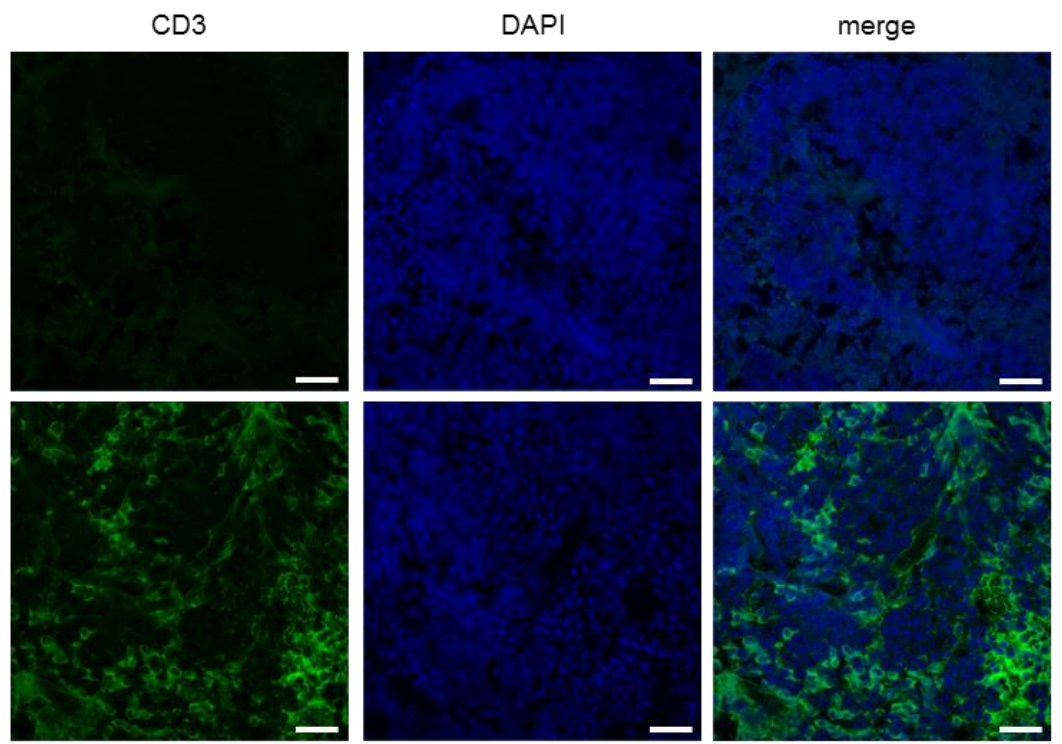

vehicle + isotype
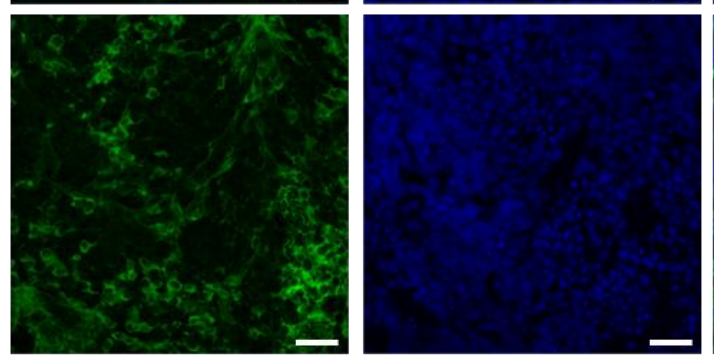

Lomitapide + isotype
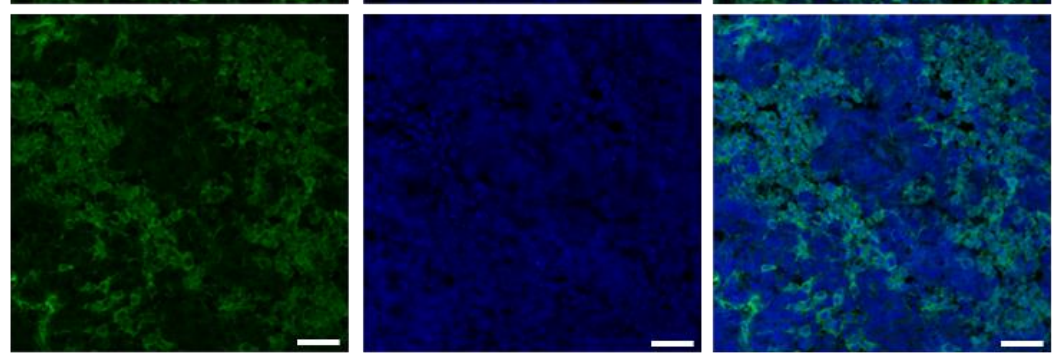

vehicle + anti-PD-1 mAb
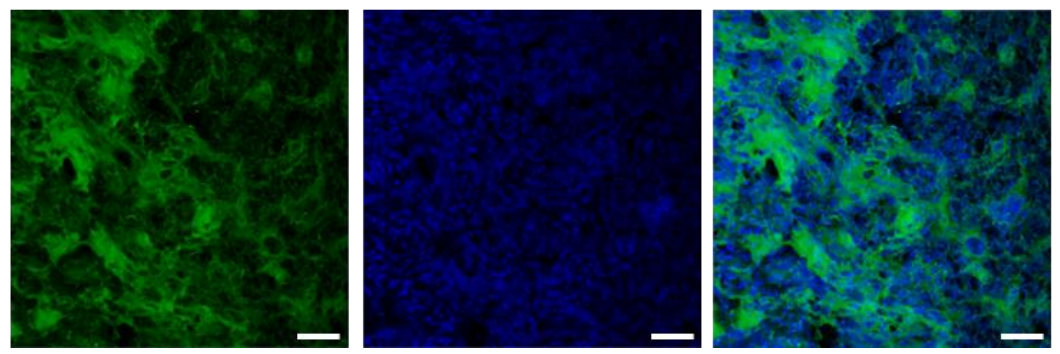

Lomitapide + anti-PD-1 mAb 


\section{Supplementary Figure 7}

a Tumor growth curves of B16F10 mouse melanoma cells in mice treated with control (vehicle) or lomitapide combined with either control isotype or anti-PD-1. Lomitapide at $20 \mathrm{mg} / \mathrm{kg}$ everyday, anti PD-1 or isotype $\mathrm{IgG}$ at $7.5 \mathrm{mg} / \mathrm{kg}$ every other day. Statistically significant differences (indicated by asterisks) are calculated using an unpaired two-tailed Student's $t$ test $(* P<0.05, * * P<0.005$, and $* * * P<0.0005)$. b Representative images of tumor tissues at 15 days following inoculation of B16F10 cells. c Representative images of immunofluorescence staining of CD3 (green), and DAPI (blue) in B16F10 tumor tissues. Scale bar: $20 \mathrm{~mm}$. 


\section{Supplementary Table 1}

\begin{tabular}{|c|c|c|c|c|c|c|c|c|}
\hline Cell Type & Cellline & IC50 [M] & Cell Type & Cellline & IC50 [M] & Cell Type & Cellline & IC50 [M] \\
\hline Skin & A2058 & $1.40 \mathrm{E}-06$ & Brain & U87MG & $3.10 \mathrm{E}-06$ & Stomach & MKN-45 & $3.90 \mathrm{E}-06$ \\
\hline Blood & KARPAS 299 & $1.40 \mathrm{E}-06$ & Breast & MDA MB 231 & $3.20 \mathrm{E}-06$ & Breast & SK.BR-3 & $3.90 \mathrm{E}-06$ \\
\hline Colon & HT-29 & $1.60 \mathrm{E}-06$ & Lung & NCl-H441 & $3.20 \mathrm{E}-06$ & Breast & EFM-192A & $4.00 \mathrm{E}-06$ \\
\hline Skin & SK-MEL-3 & $1.60 \mathrm{E}-06$ & Lung & NCl-H82 & $3.20 \mathrm{E}-06$ & Ovary & EFO-27 & $4.00 \mathrm{E}-06$ \\
\hline Skin & A375 & $1.80 \mathrm{E}-06$ & Lung & RERF-LC-MS & $3.20 \mathrm{E}-06$ & Blood & JVM-3 & $4.00 \mathrm{E}-06$ \\
\hline Brain & A172 & $1.90 \mathrm{E}-06$ & Endometrium & RL95-2 & $3.20 \mathrm{E}-06$ & Lung & $\mathrm{NCl}-\mathrm{H} 1838$ & $4.00 \mathrm{E}-06$ \\
\hline Blood & K562 & $2.10 \mathrm{E}-06$ & Brain & SK-N-SH & $3.20 \mathrm{E}-06$ & Lung & HCC 827 & $4.10 \mathrm{E}-06$ \\
\hline Blood & OCI-AML3 & $2.10 \mathrm{E}-06$ & Colon & T84 & $3.20 \mathrm{E}-06$ & Lung & BEN & $4.20 \mathrm{E}-06$ \\
\hline Blood & RPMI 8226 & $2.10 \mathrm{E}-06$ & Blood & HL-60 & 3.30E-06 & Blood & M07e & $4.20 \mathrm{E}-06$ \\
\hline Ovary & SNU840 & $2.30 \mathrm{E}-06$ & Breast & IIMT-1 & $3.30 \mathrm{E}-06$ & Prostate & PC3 & $4.30 \mathrm{E}-06$ \\
\hline Blood & U-937 & $2.30 \mathrm{E}-06$ & Blood & MEC-1 & 3.30E-06 & Blood & OPM-2 & $4.40 \mathrm{E}-06$ \\
\hline Brain & SK-N-MC & $2.40 \mathrm{E}-06$ & Lung & $\mathrm{NCl}-\mathrm{H} 2009$ & 3.30E-06 & Colon & DLD-1 & $4.50 \mathrm{E}-06$ \\
\hline Stomach & Hs 746T & $2.50 \mathrm{E}-06$ & Lung & $\mathrm{NCl}-\mathrm{H} 2110$ & 3.30E-06 & Ovary & MCAS & $4.50 \mathrm{E}-06$ \\
\hline Colon & SW480 & $2.50 \mathrm{E}-06$ & Stomach & NCI-N87 & $3.30 \mathrm{E}-06$ & Pancreas & PANC-1 & $4.50 \mathrm{E}-06$ \\
\hline Brain & U118MG & $2.50 \mathrm{E}-06$ & Ovary & OVK18 & $3.30 \mathrm{E}-06$ & Colon & SW948 & $4.50 \mathrm{E}-06$ \\
\hline Lung & RERF-LC-Ad2 & $2.60 \mathrm{E}-06$ & Colon & RKO & 3.30E-06 & Brain & $\mathrm{H} 4$ & 4.60E-06 \\
\hline Ovary & A2780 & $2.70 \mathrm{E}-06$ & Ovary & SK-OV3 & 3.30E-06 & Lung & SK-LU-1 & 4.60E-06 \\
\hline Lung & COR-L279 & $2.70 \mathrm{E}-06$ & Colon & Colo 205 & $3.40 \mathrm{E}-06$ & Lung & $\mathrm{NCl}-\mathrm{H} 1573$ & $4.70 \mathrm{E}-06$ \\
\hline Liver & Нер3В2.1-7 & $2.70 \mathrm{E}-06$ & Colon & LOVO & $3.40 \mathrm{E}-06$ & Lung & H1299 & $4.80 \mathrm{E}-06$ \\
\hline Brain & LN229 & $2.70 \mathrm{E}-06$ & Lung & $\mathrm{NCl}-\mathrm{H} 2286$ & $3.40 \mathrm{E}-06$ & Ovary & ov56 & $4.80 \mathrm{E}-06$ \\
\hline Blood & OCI-AML5 & $2.70 \mathrm{E}-06$ & Brain & SK-N-FI & $3.40 \mathrm{E}-06$ & Endometrium & HEC-1-A & $4.90 \mathrm{E}-06$ \\
\hline Kidney & Caki-2 & $2.80 \mathrm{E}-06$ & Colon & HCT-15 & 3.50E-06 & Breast & BT-20 & $5.00 \mathrm{E}-06$ \\
\hline Breast & MCF-7 & $2.80 \mathrm{E}-06$ & Blood & KMS-12-BM & $3.50 \mathrm{E}-06$ & Prostate & DU-145 & $5.00 \mathrm{E}-06$ \\
\hline Blood & OCI-LY19 & $2.80 \mathrm{E}-06$ & Prostate & LnCap & $3.50 \mathrm{E}-06$ & Colon & HCT116 & $5.00 \mathrm{E}-06$ \\
\hline Stomach & SNU-1 & $2.80 \mathrm{E}-06$ & Bone & SK-ES-1 & 3.50E-06 & Lung & DV90 & $5.20 \mathrm{E}-06$ \\
\hline Bone & U2OS & $2.80 \mathrm{E}-06$ & Lung & A549 & 3.60E-06 & Lung & $\mathrm{H} 2228$ & $5.30 \mathrm{E}-06$ \\
\hline Kidney & A498 & $2.90 \mathrm{E}-06$ & Pancreas & AsPC-1 & $3.60 \mathrm{E}-06$ & Lung & $\mathrm{NCl}-\mathrm{H} 1563$ & $5.30 \mathrm{E}-06$ \\
\hline Breast & HCC 1569 & $2.90 \mathrm{E}-06$ & Kidney & Caki-1 & $3.60 \mathrm{E}-06$ & Ovary & OVCAR-3 & $5.30 \mathrm{E}-06$ \\
\hline Pancreas & Mia PaCA 2 & $2.90 \mathrm{E}-06$ & Breast & EFM-19 & $3.60 \mathrm{E}-06$ & Stomach & Kato III & $5.40 \mathrm{E}-06$ \\
\hline Duodenum & Hutu 80 & $3.00 \mathrm{E}-06$ & Endometrium & Ishikawa & $3.60 \mathrm{E}-06$ & Blood & LP-1 & $5.40 \mathrm{E}-06$ \\
\hline Blood & Jurkat & $3.00 \mathrm{E}-06$ & Bladder & 182 & $3.60 \mathrm{E}-06$ & Brain & U251MG & $5.40 \mathrm{E}-06$ \\
\hline Skin & MDA MB 435 & $3.00 \mathrm{E}-06$ & Blood & MOLT-4 & $3.60 \mathrm{E}-06$ & Lung & $\mathrm{NCl}-\mathrm{H} 1048$ & $5.50 \mathrm{E}-06$ \\
\hline Lung & $\mathrm{NCl}-\mathrm{H} 292$ & $3.00 \mathrm{E}-06$ & Bone & Saos-2 EC & $3.60 \mathrm{E}-06$ & Pancreas & BxPC-3 & $5.70 \mathrm{E}-06$ \\
\hline Lung & SCLC-21H & $3.00 \mathrm{E}-06$ & Colon & SW620 & $3.60 \mathrm{E}-06$ & Blood & KG-1 & $5.70 \mathrm{E}-06$ \\
\hline Ovary & Cov434 & $3.10 \mathrm{E}-06$ & Stomach & MKN-1 & $3.70 \mathrm{E}-06$ & Lung & LOU-NH91 & $5.70 \mathrm{E}-06$ \\
\hline Lung & EPLC-272H & $3.10 \mathrm{E}-06$ & Lung & $\mathrm{NCl}-\mathrm{H} 1581$ & $3.70 \mathrm{E}-06$ & Lung & $\mathrm{NCl}-\mathrm{H} 1703$ & $5.70 \mathrm{E}-06$ \\
\hline Lung & $\mathrm{NCl}-\mathrm{H} 1437$ & $3.10 \mathrm{E}-06$ & Lung & $\mathrm{H} 460$ & $3.80 \mathrm{E}-06$ & Breast & HCC 38 & $6.00 \mathrm{E}-06$ \\
\hline Blood & P31/FUJ & $3.10 \mathrm{E}-06$ & Lung & $\mathrm{NCl}-\mathrm{H} 838$ & $3.80 \mathrm{E}-06$ & Blood & MV4-11 & $6.20 \mathrm{E}-06$ \\
\hline Bone & SJSA-1 & $3.10 \mathrm{E}-06$ & Brain & T98G & $3.80 \mathrm{E}-06$ & Blood & MOLM-13 & $6.30 \mathrm{E}-06$ \\
\hline Stomach & SNU-216 & $3.10 \mathrm{E}-06$ & Fibrosarcoma & HT-1080 & $3.90 \mathrm{E}-06$ & Endometrium & HEC-1-B & $6.90 \mathrm{E}-06$ \\
\hline
\end{tabular}

IC50 of 120 cancer cell lines treated $50 \mu \mathrm{M}$ lomitapide for $24 \mathrm{~h}$ 


\section{Supplementary Table 2}

\begin{tabular}{|c|c|c|c|c|c|}
\hline ENTREZID & Symbol & $\log F C$ & P.Value & adj.P.Val & geneType \\
\hline 54541 & DDIT4 & 5.910254822 & $5.69628 \mathrm{E}-15$ & 4.24942E-11 & upDEG \\
\hline 9451 & EIF2AK3 & 2.301367587 & 8.17191E-11 & $1.76703 \mathrm{E}-08$ & upDEG \\
\hline 23710 & GABARAPL1 & 1.241616385 & $3.28012 \mathrm{E}-09$ & $2.87582 E-07$ & upDEG \\
\hline 58476 & TP53INP2 & 1.386232127 & 3.12957E-08 & $1.77541 \mathrm{E}-06$ & upDEG \\
\hline 55062 & WIPI1 & 1.108345985 & $3.32276 \mathrm{E}-08$ & $1.84984 \mathrm{E}-06$ & upDEG \\
\hline 8408 & ULK1 & 1.141061268 & $3.90572 \mathrm{E}-08$ & 2.11135E-06 & upDEG \\
\hline 83452 & RAB33B & 1.151984194 & $1.83425 \mathrm{E}-07$ & 7.29788E-06 & upDEG \\
\hline 8660 & IRS2 & 0.906453176 & $2.72059 \mathrm{E}-07$ & 9.94882E-06 & upDEG \\
\hline 8878 & SQSTM1 & 0.898139861 & $1.38666 \mathrm{E}-06$ & $3.97865 \mathrm{E}-05$ & upDEG \\
\hline 23130 & ATG2A & 1.057396882 & $1.42382 \mathrm{E}-06$ & 4.06963E-05 & upDEG \\
\hline 2081 & ERN1 & 1.652389541 & $1.23196 \mathrm{E}-05$ & 0.000236867 & upDEG \\
\hline 53349 & ZFYVE1 & 0.885644984 & $1.26852 \mathrm{E}-05$ & 0.000242644 & upDEG \\
\hline 9821 & RB1CC1 & 0.690855441 & $2.25737 \mathrm{E}-05$ & 0.000388466 & upDEG \\
\hline 9776 & ATG13 & 0.592264023 & $3.69652 \mathrm{E}-05$ & 0.00058362 & upDEG \\
\hline 7405 & UVRAG & 0.654276038 & $4.02276 \mathrm{E}-05$ & 0.000624553 & upDEG \\
\hline 29982 & NRBF2 & 0.67656733 & $4.36148 \mathrm{E}-05$ & 0.000663336 & upDEG \\
\hline 8897 & MTMR3 & 0.892307328 & $4.92182 \mathrm{E}-05$ & 0.000733602 & upDEG \\
\hline 55626 & AMBRA1 & 0.682142036 & $4.95355 \mathrm{E}-05$ & 0.000737595 & upDEG \\
\hline 3091 & HIF1A & 0.863816687 & 0.000372191 & 0.003803483 & upDEG \\
\hline 5170 & PDPK1 & 0.702664809 & 0.000526645 & 0.005027218 & upDEG \\
\hline 55102 & ATG2B & 0.983553584 & 0.000545186 & 0.005174414 & upDEG \\
\hline 9140 & ATG12 & 0.484977509 & 0.000976619 & 0.008274368 & upDEG \\
\hline 9110 & MTMR4 & 0.486483521 & 0.003840825 & 0.024818153 & upDEG \\
\hline 55578 & SUPT2OH & 0.519326456 & 0.005676427 & 0.03378842 & upDEG \\
\hline 5567 & PRKACB & -0.524460685 & 0.000103437 & 0.001339656 & dwDEG \\
\hline
\end{tabular}

List of autophagy-controlling DEGs changed in lomitapide-treated HCT116 cells. 